\title{
Stochastically-Driven Multidecadal Variability of the Atlantic Meridional Overturning Circulation in CCSM3
}

\author{
Young-Oh Kwon ${ }^{1}$ and Claude Frankignoul ${ }^{2}$ \\ 1: Woods Hole Oceanographic Institution, Woods Hole, Massachusetts, USA \\ 2: LOCEAN/IPSL, Université Pierre et Marie Curie, Paris, France
}

Submitted to Climate Dynamics on August 19, 2010

Revision submitted on February 2, 2011

Corresponding Author Address: Dr. Young-Oh Kwon, Physical Oceanography Department, Woods Hole Oceanographic Institution, MS\#21, Woods Hole, MA 02543.

E-mail: yokwon@whoi.edu 


\begin{abstract}
The Atlantic meridional overturning circulation (AMOC) in the last 250 years of the 700-yearlong present-day control integration of the Community Climate System Model version 3 with T85 atmospheric resolution exhibits a red noise-like irregular multi-decadal variability with a persistence longer than 10 years, which markedly contrasts with the preceding 300 years of very regular and stronger AMOC variability with 20 year periodicity. The red noise-like multidecadal AMOC variability is primarily forced by the surface fluxes associated with stochastic changes in the North Atlantic Oscillation (NAO) that intensify and shift northward the deep convection in the Labrador Sea. However, the persistence of the AMOC and the associated oceanic anomalies that are directly forced by the NAO forcing does not exceed about 5 years. The additional persistence originates from anomalous horizontal advection and vertical mixing, which generate density anomalies on the continental shelf along the eastern boundary of the subpolar gyre. These anomalies are subsequently advected by the mean boundary current into the northern part of the Labrador Sea convection region, reinforcing the density changes directly forced by the NAO. As no evidence was found of a clear two-way coupling with the atmosphere, the multi-decadal AMOC variability in the last 250 years of the integration is an ocean-only response to stochastic NAO forcing with a delayed positive feedback caused by the changes in the horizontal ocean circulation.
\end{abstract}




\section{Introduction}

The Atlantic Meridional Overturning Circulation (AMOC) carries warm upper waters into northern latitudes and returns cold deep waters across the Equator. Its large heat transport has a substantial influence on climate. Most simulations with state-of-the-art climate models suggest that the global warming will result in a slowdown of the AMOC, but there is a considerable spread among the predicted rate of decrease (Gregory et al. 2005). The simulations also exhibit a pronounced decadal to centennial AMOC variability in global warming as well as present-day conditions. Since many characteristics of this natural AMOC variability remain similar, they represent a major uncertainty in predicting future changes and need to be understood.

Bryden et al. (2005) presented observational evidence suggesting a recent slowing of the AMOC based on hydrographic sections at $25^{\circ} \mathrm{N}$, but a follow-up study showed that the intraannual variability of the AMOC is too large to detect such a downward trend from the temporally sparse observations (Cunningham et al. 2007). Similarly, the year-to-year variability of the North Atlantic deep western boundary current was found to be too large to detect a trend (Schott et al. 2006; Toole et al. 2010). The Atlantic Multidecadal Oscillation (AMO) index, which has been estimated from the sea surface temperature record of the last century and over longer periods from proxy data, is thought to be associated with the AMOC (e.g., Knight et al. 2005; Zhang 2008), and it exhibits large low-frequency variations (e.g., Delworth and Mann 2000). However, the AMO is also affected by global warming and other forcing (e.g. Trenberth and Shea 2006) so that it may not provide a faithful picture of the AMOC changes. Since the observations are yet too sparse to document the AMOC decadal variability, an understanding of its mechanisms must rely on model studies. 
While most climate models exhibit a pronounced multi-decadal AMOC variability, they show a variety of behavior, so that a consensus on the dominant mechanisms of AMOC variability is yet to be reached. In most models, the low-frequency AMOC fluctuations critically involve salinity changes. Delworth et al. (1993) showed that during a phase of weak AMOC, the reduced northward heat transport in their model resulted in the development of a pool of cold, dense water in the North Atlantic. This enhanced the subpolar gyre circulation and the salt transport into the sinking region, which generated more convection. The AMOC then strengthened and enhanced the northward heat transport, eventually reversing the phase of the multidecadal oscillation. A reduced freshwater transport from the Arctic also contributed to the salinity increase in the convective region (Delworth et al. 1997). A similar mechanism is at play in HadCM3, but with a shorter decadal time scale (Dong and Sutton 2005), and in MPI-OM, but with a longer dominant period, a stronger influence of sea ice and freshwater exchanges with the Arctic, and a larger role of the Nordic Seas gyre (Jungclaus et al. 2005). Remotely forced salinity anomalies may play a role, as Vellinga and Wu (2004) found that the centennial AMOC variability in HadCM3 was largely driven by salinity anomalies advected from the tropical Atlantic, although Hawkins and Sutton (2007) argued that they came from the Arctic. An influence of tropical salinity changes originating from the tropics was also detected in the simulations of Latif et al. (2000), Thorpe et al. (2001), and Mignot and Frankignoul (2005). On the other hand, Zhu and Jungclaus (2008) suggested that temperature advection controls their 30-year AMOC variability, and Danabasoglu (2008) suggested that the temperature and salinity anomalies contribute almost equally to the 20-year AMOC variability in the Community Climate System Model version 3 (CCSM3). The observations are too limited to document the relative importance of salinity and temperature on long time scales, but salinity seems to have a lesser 
influence than heat content on interannual to decadal time scales. Curry and McCartney (2001) found relatively little contribution from salinity to the changes in the Labrador Sea and Subpolar gyre density based on historical observations. Häkkinen (1999) found that Great Salinity Anomalies (GSAs) strongly reduced the deep convection in the Labrador Sea and weakened the AMOC by up to $20 \%$ in an ocean general circulation model (OGCM) hindcast, but Haak et al. (2003) found in a higher resolution ocean model that the AMOC was barely affected by the GSAs. Using other oceanic hindcasts, Eden and Jung (2001) found that the NAO forcing of the AMOC was dominated by heat flux, with freshwater flux playing a minor role; Bentsen et al. (2004), Mauritzen et al. (2006), and Frankignoul et al. (2009) concluded that salinity was only playing a passive role in the subpolar gyre on interannual to decadal time scales.

Horizontal circulation changes alter the advection of salinity and temperature, but it is not clear how the subpolar gyre circulation and the Gulf Stream - North Atlantic Current changes are related to the AMOC. Bersch (2002) and Hatun et al. (2005) suggested that weakening and contraction of the subpolar gyre increases the influence of subtropical water advected into the eastern subpolar gyre, resulting in a saltier upper ocean in the area. Häkkinen and Rhines (2004, 2009) found that the subpolar gyre has slowed down during the 1990s when deep water formation declined. As discussed in Kwon et al. (2010), the weakening of the subpolar gyre was reproduced in an eddy-permitting hindcast, and it was highly correlated with a weakening of the AMOC and a northward shift of the Gulf Stream, consistent with earlier simulations (de Coëtlogon et al. 2006). On the other hand, Zhang (2008) suggested, based on the GFDL CM2.1 control integration, that the observed decrease in subpolar gyre intensity was correlated with a strengthening of the AMOC and a southward shift of the Gulf Stream due to the increased deep western boundary current (see Zhang and Vallis 2006). Such relation between Gulf Stream shifts 
and the AMOC seems consistent with the observations (Joyce and Zhang 2010), but the Gulf Stream has not really shifted since the1990s (Peña-Molino and Joyce 2008).

The role of ocean-atmosphere coupling has been a subject of controversy. In several coupled models, the AMOC responds primarily passively to atmospheric forcing. Delworth and Greatbatch (2000) showed that stochastic anomalous surface heat flux was the dominant forcing of the multi-decadal AMOC variability in the early GFDL model, while freshwater and momentum flux played a minor role. Dong and Sutton (2005) and Jungclaus et al. (2005) also suggested that stochastic atmospheric forcing was the main driver of the AMOC changes in their climate model, with the ocean setting the AMOC time scale. However, Zhu and Jungclaus (2008) found a 30-year AMOC variability in a coupled simulation that reflected an ocean-only mode, while two-way ocean-atmosphere interactions in the North Atlantic were the dominant players in Timmermann et al. (1998). Danabasoglu (2008) also suggested that an active oceanatmosphere coupling was associated with the strong decadal AMOC and NAO variability in CCSM3, while Msadek and Frankignoul (2009) found a weak positive feedback between the Eastern Atlantic pattern and the AMOC in IPSL-CM4.

The relative influence of the deep convection sites on the AMOC variability remains also uncertain. The deep and bottom water masses in the North Atlantic are mainly formed in the Greenland-Iceland-Norwegian (GIN) Sea, the Labrador Sea, and the Irminger Sea. Eden and Willebrand (2001) suggested that NAO forcing in the Labrador Sea was mainly responsible for the interannual to decadal variability of the AMOC in their oceanic hindcast, while Schweckendiek and Willebrand (2005) presented evidence that the convection in the GIN Sea plays the dominant role at longer time scales. Deshayes and Frankignoul (2008) reported that, in another oceanic hindcast, the decadal AMOC fluctuations were primarily driven by the response 
of deep convection in the Irminger Sea to NAO changes. A limited influence of the Labrador Sea on the AMOC is also suggested by the observations (Pickart and Spall 2007). Mauritzen and Häkkinen (1999) and Straneo (2006) emphasized that the rate of dense water formation and the AMOC are not linearly related because of the distinction between diapycnal and vertical mass flux, and the role of the boundary currents. Therefore, it is important to understand the relative importance and interplay among the different deep convection sites. However, most climate models have low horizontal resolution, so that convection only takes place in one or two broad regions, and the Nordic Seas overflows are not properly represented, which alters the exchanges between the GIN Sea and the subpolar gyre.

Some coupled models exhibit multiple regimes of AMOC variability with different dominant frequencies, even though the differences between regimes have rarely been investigated (e.g., Delworth and Greatbatch 2000; Hawkins and Sutton 2007). Zhu and Jungclaus (2008) attributed the alternating 30-yr and 60-yr AMOC variability in their simulation to an ocean-only mode and an atmosphere-ocean coupled mode, respectively. Two different regimes of decadal AMOC variability are also apparent in a 700-year control simulation with CCSM3 (Danabasoglu 2008). As illustrated in Fig. 1, the maximum AMOC strength exhibits a strong variability with a 20-year period between about year 150 and 450. Danabasoglu (2008) found that the NAO has a strong 20-year variability during these 300 years, and he suggested that it modulates the subpolar gyre strength, which alters the density in the deep water formation region, leading to AMOC changes after 3-5 years. He speculated that the 20-year NAO variability was due to a two-way atmosphere-ocean coupling that involved the atmospheric response to the meridional shifts of the Gulf Stream - North Atlantic Current, which were associated with the AMOC variability. Around year 450, there is an abrupt transition to a regime of weaker and more irregular 
multidecadal variability (Fig. 1). This red noise-like AMOC regime has not been investigated and the causes of the sudden transition between the two periods need to be understood.

In this paper, we focus on the last 250 years of the CCSM3 integration with weaker irregular variability, which will be shown to reflect somewhat different mechanisms than in the preceding period. Section 2 describes the model and analysis methods. The variability of the AMOC is examined in section 3 and a mechanism is proposed to explain its red noise-like multi-decadal variability. The difference between the two regimes is discussed in section 4 .

\section{Model description and analysis methods}

The CCSM3 T85x1 consists of atmosphere, ocean, sea ice, and land models mutually linked by means of a coupler (Collins et al. 2006). The atmospheric component is the Community Atmosphere Model version 3 (CAM3), which has 26 vertical levels and T85 horizontal resolution $\left(=\sim 1.4^{\circ}\right.$ resolution). Note that there are also two lower resolution versions of CCSM3 at T42x1 and T31x3. The Parallel Ocean Program version 1.4 (POP1.4) is the ocean component, which has a horizontal resolution of $1.125^{\circ}$ in the zonal direction and a meridional resolution of $0.27^{\circ}$ at the equator gradually increasing to a maximum of $\sim 0.6^{\circ}$ at about $40^{\circ} \mathrm{N}$. There are 40 levels in the vertical, whose thickness monotonically increases from 10 m near the surface to 250 $\mathrm{m}$ in the deep ocean below $1500 \mathrm{~m}$. The other models are the Community Land Model version 3 (CLM3) and, the Community Sea Ice Model version 5 (CSIM5), which have the same horizontal resolution as the atmospheric and ocean component models, respectively.

The control integration is intended to simulate the "present day" climate, with greenhouse gases concentrations set to their 1990 levels. The ocean model was initialized from rest with the 
January mean climatological temperature and salinity from Levitus et al. (1998) and, for the Arctic Ocean, Steele et al. (2001). The atmosphere, land, and sea ice components were initialized with January conditions obtained from stand-alone integrations. The CCSM3 T85x1 control integration was run for 700 years without any flux adjustment, as documented in Collins et al. (2006). The mean AMOC exhibits a maximum strength of about $20 \mathrm{~Sv}$, located near $40^{\circ} \mathrm{N}$ and $1200 \mathrm{~m}$ (Fig.1a), which is consistent with the observations, albeit slightly stronger (e.g. Talley 2003). After an initial adjustment, the AMOC reaches a regime with strong decadal oscillations with a dominant period of about 20 year and an amplitude of 4 Sv for about 300 years (year 150449), which has been investigated by Danabasoglu (2008). The regime then changes, showing weaker and more random fluctuations of about $2 \mathrm{~Sv}$ in the last 250 years of the control integration. This study primarily focuses on the second regime (model years 450-699).

The mean fields of the simulation are broadly realistic but exhibit some significant biases in the North Atlantic, which are commonly found in global climate models of similar resolution. In particular, although the separation of the Gulf Stream is rather realistic, the path of the Gulf Stream-North Atlantic Current is too zonal near the Tail of the Grand Banks (Fig.2a; Large and Danabasoglu 2006), resulting in absence of the Northwest Corner $\left(\sim 50^{\circ} \mathrm{N}, 44^{\circ} \mathrm{W}\right)$ and a large cold and fresh biases near the surface around $40^{\circ}-50^{\circ} \mathrm{N}, 50^{\circ}-20^{\circ} \mathrm{W}$ (Danabasoglu 2008). The main deep convection site in the North Atlantic, where the mean mixed layer depth (MLD) reaches $800 \mathrm{~m}$ in winter (Fig. 2c), is centered in the western subpolar gyre near $54^{\circ} \mathrm{N}, 45^{\circ} \mathrm{W}$. This site (indicated in this and following figures by the bigger green box) extends too much to the southeast and not enough into the Labrador Sea since the cyclonic boundary current does not penetrate enough north, due to the limited horizontal resolution. Secondary convection sites are located southwest of Iceland in the Irminger Current, and in the northwestern Nordic Sea, but as 
in most OGCMs, the deep overflow water is poorly represented. Although there are small differences with the strong oscillatory regime (Fig. 2), the mean fields are similar to that discussed in Danabasoglu (2008).

Standard statistical methods, including empirical orthogonal function (EOF) analysis, lag correlation and regression, and spectral analysis are used. The mean annual cycle is removed by subtracting the 250-year long-term monthly means from each month. All the analyses are based on annual means, except for the MLD, which is averaged for the winter months (JanuaryMarch). EOFs are computed from the covariance matrix of input time series, and are displayed as regression maps on the corresponding normalized principal component $(\mathrm{PC})^{1}$, so that the EOFs show the typical amplitude of the fluctuations. All time series are linearly detrended before calculating correlation, regression, or power spectrum, although the results were not sensitive to the detrending. The statistical significance of the correlation or regression coefficients is assessed with a two-sided Student's $t$-test using an effective temporal degree of freedom taking into account the serial autocorrelation at lag 1 (Trenberth 1984; Bretherton et al. 1999). For low-pass filtered time series, the autocorrelations at the low-pass cut-off year was used instead. A 5-point smoothing in the frequency domain is applied to the spectra.

\section{The variability of the AMOC}

a. AMOC and deep convection

The AMOC variability is examined based on the leading EOFs of the zonally averaged streamfunction (Fig. 3). The first EOF, which explains $46 \%$ of the total variance, exhibits a

\footnotetext{
${ }^{1}$ Also often referred to as EOF coefficient or EOF time series
} 
deepening and slight strengthening of the mean AMOC streamfunction in Fig. 1a. The PC (PC-1) is dominated by irregular multi-decadal variability (Fig.3c). It is highly correlated with the maximum AMOC time series in Fig. 1b $(r=0.84)$ and therefore used as the base time series of the AMOC variability in the rest of the paper. The power spectrum and the autocorrelation function coarsely resemble a first order auto-regressive process (red noise) with a decorrelation time of about 10 years (Fig.4). However, there is more power near the low-frequency limit and an insignificant peak around 40-years. Note that the maximum AMOC time series exhibits a small but significant 40-year spectral peak (not shown), but it is not a robust feature.

The second EOF exhibits a smaller overturning cell confined to the north of $25^{\circ} \mathrm{N}$ accompanied by an opposite cell with similar strength to the south (Fig. 3b). PC-2 is dominated by higher frequencies than PC-1 or the maximum AMOC time series (Fig.3d). Its power spectrum is nearly white with a slight increase around 10-15 years (not shown). The correlation between PC- 1 and PC-2 is maximum with $r=\sim 0.2$ when PC-2 leads PC-1 by 1-3 years (not shown), which is consistent with a southward expansion of AMOC fluctuations, as seen in many models (e.g., Deshayes and Frankignoul 2008). With only 13\% of total variance explained and temporal characteristic different from that of maximum AMOC time series, no further consideration is given to the second mode. However, note that the first two AMOC EOFs in the preceding oscillatory regime exhibit very similar spatial patterns, but their PC-1 and 2 are highly correlated in quadrature, unlike in the present regime (not shown). Such change in the relation between the leading EOF modes in the two regimes is found for most variables, e.g. MLD and barotropic stream function.

The variability of the winter MLD is concentrated in the Labrador Sea, where the mean winter MLD is maximum and the standard deviation reaches $500 \mathrm{~m}$, versus $200 \mathrm{~m}$ and $100 \mathrm{~m}$ for 
the Nordic Sea and Irminger Current sites, respectively. This is reflected in the leading EOFs. EOF-1 exhibits, in this polarity, an intensification of the deep convection over the whole Labrador Sea convection site (Fig. 5a). PC-1 has a white spectrum with only weak peaks around 5-15 years, and it is only weakly correlated to AMOC PC-1, with maximum correlation $(r=\sim 0.2)$ when MLD PC-1 leads by 1-2 years. MLD EOF-2 is a north-south dipole also confined to the Labrador Sea convection zone, which indicates, in this polarity, a northward shift by $\sim 1^{\circ}$ latitude of the maximum convection (Fig.5b). MLD PC-2 is dominated by low frequencies (Fig. 5d) and is strongly correlated with AMOC PC-1 $(r=0.64)$ at zero lag, indicating that the deep convection is shifted north when the AMOC is intensified. The high correlation suggests that MLD EOF-2 is not an artifact of EOF analysis but a physical mode. However, the regression of the winter MLD on AMOC PC-1 shows that the northern pole in EOF-2 leads the southern one by 1-4 years. The northern part of the dipole, which will be shown to play a key role in the AMOC variability, is hereafter called the northern convection zone, and is indicated in this and other figures by a small green box $\left(54-57^{\circ} \mathrm{N}, 38-48^{\circ} \mathrm{W}\right)$. Note that the difference between mean winter MLDs of the two regimes (Fig. 2d) resembles EOF-2, suggesting that the latter is the dominant mode at ultra-low frequencies.

The low-frequency variability of deep convection is well characterized by a time series of the annual upper 500m density averaged over the northern convection zone, which is almost equally contributed by salinity and temperature (Fig.6a), although temperature dominates when density is averaged over the whole convection site or the subpolar gyre. This time series, hereafter called the convection index, is well correlated with the winter MLD PC-2 (Fig. 6b). The maximum correlation is 0.56 at zero lag with significant correlation remaining over 0.3 when the convection index leads by up to 20 years. On the other hand, the correlation drops 
below 0.3 within 5 years when MLD PC-2 leads, consistent with the MLD anomalies primarily resulting from (slow) density changes. The convection index is even better correlated with the AMOC PC- 1 with maximum correlation of 0.70 when the convection index leads by 2 years (Fig. 6b). The asymmetry of the lag-correlation is more striking and suggests that the northern convection zone drives the low-frequency AMOC variability. In addition, the small positive correlation of $\sim 0.2$ when the AMOC PC- 1 leads by up to 20 years is suggestive of a weak positive feedback of the AMOC onto the deep convection. In other words, the density in the northern convection region drives the AMOC variability, but the latter seems to sustain the convection, which may contribute to the long time scale of the AMOC, as discussed further in section 3d.

\section{b. North Atlantic Oscillation and associated surface fluxes}

The NAO is the dominant atmospheric forcing of the oceanic circulation variability in the North Atlantic, as in the observations (Visbeck et al. 2003). The leading EOF of the annual mean sea-level pressure (SLP) is realistic and the power spectrum of the corresponding PC, called the NAO index, is nearly white (Fig. 7). The NAO index is slightly skewed with a longer tail of negative values resulting in a small asymmetry in the ocean response to the NAO discussed in section 3c (i.e. stronger response for negative NAO). The correlation between the NAO index and AMOC PC- 1 is maximum when the NAO leads by $1-2$ years with $r=\sim 0.3$, and it remains significant when NAO leads by up to 4 years, which indicates a weak forcing of the AMOC by the NAO (Fig. 7c). The lag-correlation suggests very little feedback, if any, from the AMOC to the NAO. Very similar results are obtained by regressing SLP on AMOC PC-1, confirming that 
the NAO is the dominant atmospheric mode that forces the AMOC, as in most oceanic hindcasts (Eden and Willebrand 2001; Deshayes and Frankignoul 2008).

To document how the NAO drives the AMOC, the surface fluxes associated with a positive phase of the NAO are shown in Fig. 8. The wind stress curl is negative between $\sim 35^{\circ}$ and $58^{\circ} \mathrm{N}$ (Fig. 8a), which would drive a northward migration of the Gulf Stream - North Atlantic Current via the so-called anticyclonic intergyre gyre (Marshall et al. 2001). Further north, positive wind stress curl anomalies would intensify the cyclonic circulation and the East Greenland current. The net surface heat flux is broadly similar to the observed one (Marshall et al. 2001) (Fig. 8b). The positive (upward) heat flux anomalies have two maxima in the subpolar gyre, one in the eastern side and another one near the main convection site. As in the observations, the heat flux anomalies drive SST anomalies, except near the strong ocean currents where it damps the SST anomalies that are mainly driven by advection changes (Fig. 8c).

The surface fresh-water flux associated with the NAO can be separated into evaporation minus precipitation (E-P) and melt water flux. The E-P anomalies are generally positive throughout the subpolar gyre with maximum south of Greenland and west of the British Isles, and negative in the Nordic Sea (Fig. 8d). They are broadly consistent with the observed anomalies (Visbeck et al. 2003; Josey and Marsh 2005) but 30-50\% smaller, although the climatological E and P are realistic. The surface heat flux and E-P associated with a positive NAO phase thus both increase the density of the upper ocean in most of the subpolar gyre, and in particular at the main convection site.

The NAO melt water flux is below average (red) in a narrow band along the in-shore side of the boundary current near southern Greenland and in the Labrador Sea, while it is above average (blue) off-shore (Fig. 8e). Note that minus the melt water flux anomalies are plotted in Fig. 8e for 
consistency with E-P and surface salinity plots, i.e. blue corresponds to freshening. The sea-ice concentration increases by $2-5 \%$ near the Labrador Sea boundary currents when the NAO is positive (not shown), as in the observations (Chapman and Walsh 1993; Deser et al. 2000). More sea-ice is then advected off-shore by anomalous currents, melting and freshening the upper ocean in the off-shore side of the boundary current, as in the climatological annual cycle in CCSM2 (Bitz et al. 2005). Since the amplitude of the melt water flux anomalies is 2 to 10 times greater than that of E-P (note the different contour intervals), the excessive melt water flux in positive NAO years make the density lighter around the convection site, while at most of the convection site the positive E-P offsets the melt water influence.

\section{c. Ocean response to the North Atlantic Oscillation}

In this section, we examine to what extent the long persistence of the AMOC variability in this regime may be explained by the ocean integrating the NAO forcing, which acts as a stochastic forcing since the associated yearly surface flux exhibit no persistence beyond one year.

In a positive NAO phase, the upper ocean becomes rapidly denser in most of the subpolar gyre and at the northern convection site, primarily due to anomalous cooling, while it changes little in the southern convection region where freshening and anomalous advection partially balance cooling (Fig.9a). In addition, the density decreases along the boundary current west and south of the convection zone, reflecting the positive melt water flux and the local heating. Hence, the NAO buoyancy flux rapidly enhances deep convection in the northern convection zone and increases its density gradient with the Labrador Current (Fig. 9a). When density lags the NAO, the positive density anomalies slowly propagate from the eastern subpolar gyre toward the 
(northern) convection site and along the West Greenland current into the Labrador Sea, then off Newfoundland (Fig. 9). In the northern convection zone, the maximum NAO influence thus occurs at lag 1 (correlation $r=0.37$ ), consistent with its key role in the AMOC variability.

Also noteworthy in Fig. 9 are the negative density anomalies along the Gulf Stream-North Atlantic Current. They are warm and salty, and primarily caused by the northward shift of the current due to NAO wind stress curl forcing, although at no lag buoyancy forcing dominates. As the lag increases, the North Atlantic Current density anomaly intensifies and slowly propagates downstream, extending into the eastern subpolar gyre until lag 5 (lag is hereafter in year), and then weakens, while positive density anomalies (primarily temperature controlled) appear in the eastern subpolar gyre near the British Isles, expanding for a few years (Fig. 9f). Regression at larger lag suggests that these positive density anomalies propagate along the Irminger current and into the Nordic Sea, reaching the convection region around lag 9, although by then the anomalies have become very weak. This will be seen more strikingly when the density is regressed on the convection index, so that a discussion of their origin is postponed until section 3d.

To document the vertical extent of the NAO influence, Fig. 10 shows density, meridional and vertical velocity on a zonal section along $56^{\circ} \mathrm{N}$ that crosses the northern convection zone, regressed onto the NAO time series. The mean density contours (in grey) exhibit a typical doming of the density surfaces in the northern convection zone (indicated by the green bar). At lag 0 , there are positive density anomalies in the upper ocean east of $50^{\circ} \mathrm{W}$, reaching down to 1200 $\mathrm{m}$ in the convection site (Fig. 10a). To the west, there are shallow negative density anomalies resulting in an anomalous zonal density gradient in the upper ocean, which generates a southward geostrophic shear flow near the eastern edge of the convection zone (Fig. 10d). The 
vertical gradient of the meridional velocity is $\sim 3 \times 10^{-5} \mathrm{~s}^{-1}$ near the surface, which is consistent with the estimate based on the thermal wind relation with $\sim 0.1 \mathrm{~kg} \mathrm{~m}^{-3}$ change over $\sim 5^{\circ}$ longitude.

As the lag increases, the dense anomalies extend towards the western boundary and penetrate deeper (Fig. 10a-c). This might be due to cyclonic advection and increased diffusion, since the resulting intensification of the Labrador Current increases the slope of the isopycnal, which increases the mixing due to the Gent-McWilliams isopycnal transport parameterization in CCSM3 (Gent and McWilliams 1990). Figure 10g-i shows that the vertical velocity anomalies are mostly concentrated near the boundary and very weak in the convection zone. Water mass transformation occurs in the convection zone but the actual sinking of dense water can only happen near boundaries where the horizontal velocity normal to the boundary is supported by the along-boundary pressure gradient (Spall and Pickart 2001; Spall 2004). The vertical velocity anomalies near the western boundary are initially upward because the upper ocean density is lighter north of the section and denser south of it (Fig. 9a; Spall 2008). When at lag 2 the dense water anomalies reach the boundary near the surface (c.f. Straneo et al. 2003), the alongboundary density gradient changes sign and there is anomalous sinking (Fig. 9c, 10i) while southward current anomalies become more barotropic (Fig. 10e-f) (Straneo 2006). The dense water anomalies propagate equatorward along the western boundary at depth (Fig. 11), enhancing the deep zonal density gradient and the AMOC, and consistent with wave propagation in the model (Kawase 1987; Johnson and Marshall 2004). The interaction of the Gulf Stream with these deep anomalies (Zhang and Vallis 2007) perhaps explains why the Gulf Stream returns toward its climatological position while the North Atlantic Current remains shifted northward, as also shown in Fig. 12d. East and over most of the convection site, the velocity anomalies are northward at $\operatorname{lag} \geq 1$ (Fig. 10d -f), reflecting the negative density anomalies due to 
the North Atlantic Current shift seen in Fig. 9. Therefore, the cyclonic gyre around the convection site intensifies, which may further shoal the isopycnal surfaces and thus sustain the convection. This positive feedback increases the persistence of the convection and the overall oceanic response to the NAO, as further discussed in the section 4.

The response of the barotropic streamfunction (Fig. 12) initially exhibits the typical anticyclonic intergyre gyre driven by the NAO wind stress curl. At lag 1, the anticyclonic anomaly becomes centered along the Gulf Stream-North Atlantic Current, which indicates its northward shift, while a cyclonic circulation develops near the convection site, consistent with Fig. 10. As the lag increases, the anticyclonic anomalies become narrower and propagate downstream along the North Atlantic Current (or they mainly intensify while the Gulf Stream return to its original position), as the negative density anomalies in Fig. 9, and the cyclonic anomalies around the convection site persist up to lag 5. Therefore, the cyclonic subpolar gyre intensifies and contracts in response to the NAO. The lag 1 pattern is similar to the observed seasurface height changes reported by Häkkinen and Rhines (2004), but the observations also suggest that the subpolar gyre expands towards Rockall Trough/Faroe Bank as the Labrador Sea Water volume increases (Hatun et al. 2005; Bersch et al. 2008), which is not seen here.

The AMOC response to the NAO is somewhat noisy and best seen when the low-pass filter is applied to retain periods longer than 10 years (Fig. 13a-d). The regressions exhibit a coherent anomalous overturning cell in the whole domain, which resembles AMOC EOF-1 and peaks when the AMOC lags by 1 year. However, significance is lost after lag 5, suggesting that the AMOC is driven by the stochastic NAO forcing, but more complex dynamics are at play to sustain and enhance the AMOC response. 


\section{d. Oceanic persistence}

More persistent anomalies are obtained when the variables are regressed on the convection index instead of the NAO index, as in Deshayes and Frankignoul (2008), allowing us to identify the feedback that sustains the AMOC changes. The regression of the AMOC on the convection index exhibits a persistent anomalous overturning cell that is also mostly well correlated with the AMOC EOF-1 (pattern correlation of 0.94 at lag 1), without need for low-pass filtering (Fig. 13e-h). Small but significant anomalies start to emerge near $50^{\circ} \mathrm{N}$ when the AMOC precedes convection by 5 years. The anomalies expand southward and intensify (see lag -3 in Fig. 13e-f), then very slowly decrease at greater lag, remaining significant until lag 13. Such lagged regression is consistent with Fig. 6, which more clearly suggested that a weak positive feedback is at play between the AMOC and the northern convection zone, as further examined below.

As in the regression on the NAO index, the regressions of the barotropic streamfunction and the upper 500m density anomalies on the convection index show much similarity, except in the far eastern subpolar gyre. As this region plays a key role in the AMOC persistence and the anomalies are more strikingly revealed by correlation maps, we use lagged correlation in Fig. 14. The correlation of the barotropic streamfunction with the convection index (left panels) shows features that are similar, but more persistent, to those seen in the regression on the NAO index (Fig. 12b), i.e. intensification of the cyclonic circulation near the convection site and anticyclonic anomalies along the Gulf Stream-North Atlantic Current. Comparison with Fig. 6 shows that the cyclonic gyre anomalies vary essentially in phase with AMOC PC-1.

Interestingly, there is a progressive shift between the two centers of action, which is more fully documented in Fig. 15. Indeed, the anticyclonic anomalies along the Gulf Stream-North Atlantic Current only become significant around lag -2 and grow following the maximum 
convection and the intensification of the AMOC. They reach a maximum amplitude after 4 to 9 years (Fig. 14c and red curve in Fig. 15) before slowly decaying. The cross correlation between the two indices remains significant until lag 20, but persistence seems much longer. This suggests that the progressive shift of the Gulf Stream-North Atlantic Current is a cumulative response to anomalously strong convection. Again, the small but sustained correlation at negative lag is indicative of a weak positive feedback between the North Atlantic Current and deep convection changes at the northern convection site. As in Fig. 11 (but more persistently), the increased convection is found to also generate deep positive density anomalies that propagate southward along the deep western boundary current, with maximum correlation at $35^{\circ} \mathrm{N}$ when they lag the convection index by 3 to 7 years.

The correlation of the upper 500m density anomalies with the convection index reveals the presence of very persistent anomalies in the far eastern subpolar gyre and the Nordic Sea that were not visible in barotropic streamfunction (Fig. 14 right). At lag -12, i.e. when density precedes convection by 12 years, the surface waters are denser along the eastern boundary of the basin and along the Irminger and East Greenland Currents, due to colder temperature. The lag correlation suggests that the dense eastern water slowly propagates toward the northern convection region, where the anomaly starts to grow and the water becomes saltier due to vertical mixing. At lag 0 and 1, the positive density anomalies are large and highly significant in the western subpolar gyre and much of the Nordic Sea. These are still largely controlled by temperature, except in the (anomalously salty) western part of the Nordic Sea.

When density lags the convection index further, positive density anomalies appear again along the eastern boundary and in the Nordic Sea (Fig. 14f). These anomalies became significant at lag 4 near the eastern boundary, resembling those lagging the NAO by 6 years in Fig. 9f, then 
propagated into the Nordic Sea and south of Iceland, and they are again primarily due to colder water, although the water is also more salty just north of the British Isles. At larger lags, the positive density anomalies are advected westward along the subpolar gyre and reach the northern convection zone, thereby sustaining the deep convection perturbation that was initiated by the NAO forcing. At lag 11, their pattern becomes similar to that at lag -12, suggesting a recurrent behavior (not shown). On the other hand, the negative (warm, salty) density anomalies that appeared in the North Atlantic Current intensify and expand northeastward, then even northwestward, reaching their maximum extent around lag 7 but never extending far enough to reach the convection region.

Since the positive anomalies along the eastern boundary do not show any sign of being directly forced by the atmosphere (the only correlation with local fluxes reflects local damping), they must originate in the ocean. Fig. 16 shows a close-up of the regression of horizontal velocity on the convection index at lag 7 that may explain their occurrence. There is a strong anomalous southward jet extending over the shelf break (at about $500 \mathrm{~m}$ depth) east of Ireland, which is consistent with the streamfunction anomalies in Fig. 14c. The interaction of the anomalous jet with the topography may have induced a vertical mixing that resulted in the upper ocean density increase over the continental shelf. The temperature and salinity climatology along a zonal section at $53^{\circ} \mathrm{N}$ near the eastern boundary (light blue contours in Fig. 17) indeed show a subsurface maximum around $250 \mathrm{~m}$ which is an extension of the Mediterranean Salt Tongue in this simulation. The temperature and salinity anomalies revealed by the regression are positive above the mean Mediterranean Salt Tongue and negative within the Tongue, which indicates vertical mixing. The salinity anomalies contribute most to the density near the surface, perhaps in part because the temperature anomalies are damped by the surface heat flux, but temperature 
dominates below, resulting in denser waters over the shelf that are, on the average over the upper $500 \mathrm{~m}$, dominated by temperature effects. The jet may be sustained by the increase in the zonal density gradient induced by the mixing, as suggested in the lag correlation between the two (not shown). This positive feedback perhaps explains the gradual strengthening and long persistence of the barotropic streamfunction anomalies in the North Atlantic Current (red curve in Fig. 18a) as well as the slow growth of the density anomalies near the eastern boundary. As mentioned above, the positive density anomalies near the eastern boundary seem to be recurrent at about 20year interval, and they lead after some delay to an intensification of the deep convection. Evidence of the recurrence is seen in the auto-correlation of the convection index (black curve in Fig. 18a), which drops quickly for 4 to 5 years, consistent with the response to the NAO described in the previous section, and decays more slowly until lag 16, but then bounces and becomes again significant around lag 20. This hint of an oscillatory behavior is consistent with an insignificant peak around 20 year in the raw spectrum, i.e. periodogram, of the AMOC PC-1 (not shown).

\section{Summary and discussion}

The AMOC in the last 250 years of the 700-year-long present-day control integration of the CCSM3 T85x1 exhibits a red noise-like multi-decadal variability with a broad variance maximum at a period of about 40 years, which markedly contrasts to the preceding $~ 300$ years of regular and stronger AMOC variability with $\sim 20$ year periodicity. The red noise-like multidecadal variability is primarily forced by the stochastic atmospheric forcing due to the natural variability of the NAO. The surface heat exchanges in a positive NAO phase cool the subpolar gyre and increase the density in the northern part of the main deep convection area, which is 
located slightly southeast of the observed convection site in the Labrador Sea, thus shifting the convection northward. At the same time, anomalous melt water from the sea-ice near eastern Greenland and the western boundary of the Labrador Sea gyre increases the buoyancy of the boundary currents, resulting in an anomalous density gradient that intensifies the cyclonic circulation around the convection region. This in turn lifts the isopycnal surfaces near the center of the convection region, resulting in a further increase in convection (Leverman and Born 2007). As the dense anomalies approach the western Labrador Sea boundary at depth, they sink along the slope and then propagate equatorward, presumably as western boundary wave, enhancing the AMOC. The NAO forcing also shifts the Gulf Stream-North Atlantic Current northward in a year or so, leading to warm anomalies and an anti-cyclonic circulation anomaly that intensifies and expands slowly northeastward along the North Atlantic Current. The downstream expansion may be more striking because the Gulf Stream shifts back to its original position, perhaps because of the interaction with the deep anomaly along the western boundary (Zhang and Vallis 2007). The direct response to the NAO, however, can be traced by regression analysis for merely 5 years, while AMOC anomalies persist much longer.

The additional persistence originates from a delayed positive feedback associated with the anomalous horizontal ocean circulation, better seen by regressing on or correlating with a convection index that represents the upper $500 \mathrm{~m}$ density in the northern convection zone, thus monitoring the deep convection shifts. Following the increased convection driven by the NAO, the anti-cyclonic gyre anomalies due to the northward shift of the Gulf Stream-North Atlantic Current intensify and expand slowly northeastward along the mean North Atlantic Current for about 4-9 years, resulting in southward anomalous flow over the continental shelf break near the eastern boundary off Ireland. Vertical mixing over the subsurface salinity maximum associated 
with the Mediterranean Salt Tongue results in cold and salty water anomalies over the shelf, with temperature dominating the impact on the upper $500 \mathrm{~m}$ density. The anomalous southward flow may be sustained by the zonal density gradient induced by the mixing, perhaps explaining why the NAO-driven anti-cyclonic perturbation along the North Atlantic Current is expanding and so persistent. The dense water anomalies along the eastern boundary are then advected along the subpolar gyre into the convection region, causing an additional increase in convection. This positive feedback through the anomalous ocean circulation and dense water advection from the eastern boundary provides an additional persistence to the stochastically forced AMOC variability.

The key ingredient for the positive feedback and the resulting AMOC persistence is the appearance of positive (cold) density anomalies near the eastern boundary. Several studies have suggested that density anomalies near the eastern boundary are closely related to the AMOC variability. In idealized basins, Killworth (1985) and TeRaa and Dijkstra (2002) showed that cold anomalies in the subpolar gyre induce a downwelling near the northeastern corner of the basin via thermal wind balance, which creates warm anomalies there. The resulting zonal density gradient then increases the meridional overturning, which warms the subpolar gyre and starts the opposite phase of the oscillation. However, whether the anomalies near the eastern boundary would still be found with realistic topography is unclear, as adding a sloping topography to the eastern wall substantially modifies the MOC behavior (Winton 1997; M. Buckley 2010, private communication). Nonetheless, Czeschel et al. (2010) found in an adjoint calculation with a realistic OGCM that cold anomalies near the eastern boundary led to a stronger AMOC after about 9 years and caused an oscillatory behavior, although the role of topography in the generation of the anomaly is unclear. However, the delay was due to Rossby wave propagation 
toward the western boundary followed by northward advection, instead of mean advection along the eastern boundary and the subpolar gyre, as in CCSM3. Hence, the mechanisms for the generation of density anomalies near the eastern boundary and their propagation require further studies.

The AMOC variability in the red-noise like regime (years 450-699) is thus primarily driven by temperature changes in the subpolar gyre linked to NAO forcing and oceanic advection, although salinity also contribute near the convection site, as found by Danabasoglu (2008) for the regime with stronger and more regular variability (years 150-399). The markedly distinct AMOC variability between the two regimes may result from slightly different subpolar gyre circulation, which is slightly stronger and more contracted in the oscillatory regime (Fig.2b). Recall that the negative density anomalies in the North Atlantic Current region do not reach all the way to the convection region in the red noise regime (Fig. 14f). Very similar negative density anomalies also appear in the oscillatory regime, but they propagate into the convection region (not shown), changing the sign of density anomalies there, hence reducing convection and the AMOC. This is reflected in the oscillatory behavior shown in Fig. 18b. Note that the autocorrelations of the convection index from both regimes drops similarly until about lag 5, presumably reflecting a similar response to NAO forcing (black curves in Fig. 18a-b), and that they both reach a secondary maximum around lag 20, suggesting comparable dynamics, but more inhibited behavior in the red noise regime, The resemblance between the differences in the climatology of the two regimes and the dominant patterns of variability also suggests broadly comparable dynamics. However, the slight differences result in markedly distinct AMOC regimes as the barotropic streamfunction anomalies in the North Atlantic Current region show no hint of an oscillatory behavior in the red noise regime (red curves in Fig. 18a-b). 
The air sea coupling also differs in the two regimes. In the strong oscillatory regime, the NAO spectrum exhibits enhanced variance at low frequency, with a narrow peak around 20 years (Danabasoglu 2008). In the red noise regime, the frequency spectrum of the NAO is essentially white. More refined analysis suggests that a very weak but statistically significant atmospheric response to the AMOC can be found in winter (but not in yearly fields) in the red noise regime, but not in the oscillatory regime (G. Gastineau personal communication). Hence, the different air sea coupling in the two regimes needs to be further investigated, as also the reason for the abrupt transition between them.

\section{Acknowledgments}

We wish to acknowledge helpful discussions and technical support from many colleagues

including G. Danabasoglu, M. Spall, F. Straneo, S. Jayne, and J. Deshayes, and constructive reviews by the two anonymous reviewers. We gratefully acknowledge financial support from WHOI Ocean Climate Change Institute and NOAA Climate Program Office. This work was also supported in part by the Institut universitaire de France (CF). 


\section{References}

Bentsen M, Drange H, Furevik T, Zhou T (2004) Simulated variability of the Atlantic meridional overturning circulation. Clim Dyn 22:701-720

Bersch M (2002) North Atlantic Oscillation-induced changes of the upper layer circulation in the northern North Atlantic Ocean. J Geophys Res 107 (C10):3156, doi:10.1029/2001JC000901

Bersch,M, Yashayaev I, Koltermann KP (2008) Recent changes of the thermohaline circulation in the subpolar North Atlantic. Ocean Dyn 57:223-235

Bitz CM, Holland MM, Hunke E, Moritz RE (2005) Maintenance of the sea-ice edge. J Clim 18:2903--2921

Bretherton CS, Widmann M, Dymnikov VP, Wallace JM, Bladé I (1999) The Effective Number of Spatial Degrees of Freedom of a Time-Varying Field. J Clim 12:1990-2009

Bryan FO, Danabasoglu F, Nakashiki N, Yoshida Y, Kim D-H, Tsutsui J, Doney SC (2006) Response of the North Atlantic thermohaline circulation and ventilation to increasing carbon dioxide in CCSM3. J Clim 19:2382-2397

Bryden HL, Longworth HR, Cunningham SA (2005) Slowing of the Atlantic meridional overturning circulation at $25^{\circ} \mathrm{N}$. Nature 438:655-657

Chapman WL, Walsh JE (1993) Recent variations of sea ice and air temperature in high latitudes. Bull Amer Meteor Soc 74:33-47

Collins WD, Bitz CM, Blackmon ML, Bonan GB, Bretherton CS, Carton JA, Chang P, Doney SC, Hack JJ, Henderson TB, Kiehl JT, Large WG, McKenna DS, Santer BD, Smith RD (2006) The Community Climate System Model Version 3 (CCSM3). J Clim 19:2122-2143

Cunningham ST et al (2007) Temporal variability of the Atlantic meridional overturning circulation at $26.5^{\circ} \mathrm{N}$. Science $317: 935-938$

Curry RG, McCartney MS (2001) Ocean gyre circulation changes associated with the North Atlantic Oscillation. J Phys Oceanogr 31:3374-3400

Czeschel L, Marshall DP, Johnson HL (2010) Oscillatory sensitivity of Atlantic overturning to high-latitude forcing. Geophys Res Lett 37:L10601, doi:10.1029/2010GL043177 
Danabasoglu G (2008) On multi-decadal variability of the Atlantic meridional overturning circulation in the community climate system model version 3 (CCSM3). J Clim 21:55245544

de Coëtlogon G, Frankignoul C, M Bentsen, C Delon, H Haak, S Masina, A Pardaens (2006) Gulf Steam variability in five oceanic general circulation models. J Phys Oceanogr 36:21192135

Delworth TL, Greatbatch RJ (2000) Multidecadal thermohaline circulation variability driven by atmospheric surface flux forcing. J Clim 13:1481-1495

Delworth TL, Manabe S, Stouffer R (1993) Interdecadal variations of the thermohaline circulation in a coupled ocean-atmosphere model. J Clim 6:1993-2011

Delworth TL, Manabe S, Stouffer R (1997) Multidecadal climate variability in the Greenland Sea and surrounding regions: A coupled model simulation. Geophys Res Lett 24:257-260

Delworth TL, Mann ME (2000) Observed and simulated multidecadal variability in the Northern Hemisphere. Clim Dyn 16:661-676

Deser C, Walsh JE, Timlin MS (2000) Arctic Sea Ice Variability in the Context of Recent Atmospheric Circulation Trends. J Clim 13:617-633

Deshayes J, Frankignoul C (2008) Simulated variability of the circulation in the North Atlantic from 1953 to 2003. J Clim 21:4919-4933

Dong B, Sutton RT (2005) Mechanism of interdecadal thermohaline circulation variability in a coupled ocean-atmosphere GCM. J Clim 18:1117-1135

Eden C, Willebrand J (2001) Mechanism of interannual to decadal variability of the North Atlantic circulation. J Clim 14:2266-2280

Eden C, Jung T (2001) North Atlantic interdecadal variability: oceanic response to the North Atlantic Oscillation (1865-1997). J Clim 14:676-691

Frankignoul C, Deshayes J, Curry R (2009) The role of salinity in the decadal variability of the North Atlantic meridional overturning circulation. Climate Dyn DOI:10.1007/s00382-008$0523-2$ 
Gent PR, Mcwilliams JC (1990) Isopycnal Mixing in Ocean Circulation Models. J Phys Oceanogr 20:150-155

Gregory JM, Coauthors (2005) A model intercomparison of changes in the Atlantic thermohaline circulation in response to increasing atmospheric $\mathrm{CO}_{2}$ concentration. Geophys Res Lett 32:L12703, doi:10.1029/2005GL023209

Haak H, Jungclaus J, Mikolajewicz U, Latif M (2003) Formation and propagation of great salinity anomalies. Geophys Res Lett 30:1473, doi:10.1029/2003GL017065

Häkkinen S (1999) Variability of the simulated meridional heat transport in the North Atlantic for the period 1951-1993. J Geophys Res 104:10991-11007

Häkkinen S, Rhines PB (2004) Decline of Subpolar North Atlantic Circulation During the 1990s. Science 304:555-559

Häkkinen S, Rhines PB (2009) Shifting surface currents in the northern North Atlantic Ocean. J Geophys Res 114:C04005, doi:10.1029/2008JC004883

Hatun H, Sando AB, Drange H, Hansen B, Valdimarsson H (2005) Influence of the Atlantic subpolar gyre on the thermohaline circulation. Science 309:1841-1844

Hawkins E, Sutton R (2007) Variability of the Atlantic thermohaline circulation described by three-dimensional empirical orthogonal functions. Clim Dyn 29:745-762

Johnson HL, Marshall DP (2004) Global Teleconnections of Meridional Overturning Circulation Anomalies. J Phys Oceanogr 34:1702-1722

Josey SA, Marsh R (2005) Surface freshwater flux variability and recent freshening of the North Atlantic in the eastern subpolar gyre. J Geophys Res 110:C05008, doi:10.1029/2004JC002521

Joyce TM, Zhang R (2010) On the path of the Gulf Stream and the Atlantic Meridional overturning circulation. J Clim 23:3146-3154

Jungclaus J, Haak H, Latif M, Mikolajewicz U (2005) Arctic-North Atlantic interactions and multi-decadal variability of the meridional overturning circulation. J Clim 18:4013-4031 
Kawase M (1987) Establishment of deep circulation driven by deep water production. J Phys Oceanogr 17: 2294-2316

Killworth PD (1985) A Two-Level Wind and Buoyancy Driven Thermocline Model. J Phys Oceanogr 15:1414-1432

Knight JR, Allan RJ, Folland CK, Vellinga M, Mann ME (2005) A signature of persistent natural thermohaline circulation cycles in observed climate. Geophys Res Lett 32:L20708, doi:10.1029/2005GL024233

Kwon Y-O, Alexander MA, Bond NA, Frankignoul C, Nakamura H, Qiu B, Thompson L (2010) Role of Gulf Stream, Kuroshio-Oyashio and Their Extensions in Large-Scale AtmosphereOcean Interaction: A Review. J Clim 23:3249-3281

Large WG, Danabasoglu G (2006) Attribution and impacts of upper-ocean biases in CCSM3. J Clim 19:2325-2346

Latif M, Roecker E, Mikolajewicz U, Voss V (2000) Tropical stabilization of the thermohaline circulation in a green house warming simulation. J Clim 13:1809-1813

Levermann A, Born A (2007) Bistability of the Atlantic subpolar gyre in a coarse-resolution climate model. Geophys Res Lett 34:L24605, doi:10.1029/2007GL031732

Levitus S, Boyer T, Conkright M, Johnson D, O’Brien T, Antonov J, Stephens C, Gelfeld R (1998) Introduction. Vol 1, World Ocean Database 1998, NOAA Atlas NESDIS 18, 346 pp

Marshall J, Johnson H, Goodman J (2001) A study of the interaction of the North Atlantic Oscillation with ocean circulation. J Clim 14:1399-1421

Mauritzen C, Häkkinen S (1999) On the relationship between dense water formation and the “meridional overturning cell” in the North Atlantic Ocean. Deep-Sea Res I 46:877-894

Mauritzen C, Hjøllo SS, Sandø AB (2006) Passive tracers and active dynamics: a model study of hydrography and circulation in the northern North Atlantic. J Geophys Res 111:C08014, doi:10.1029/2005JC003252 
Mignot J, Frankignoul C (2005) The variability of the Atlantic meridional overturning circulation, the North Atlantic Oscillation, and the El Ninõ-Southern Oscillation in the Bergen climate model. J Clim 18:2361-2375

Msadek R, Frankignoul C (2009) Atlantic multidecadal oceanic variability and its influence on the atmosphere in a climate model. Clim Dyn 33:45-62, DOI 10.1007/s00382-008-0452-0

Peña-Molino B, Joyce TM (2008) Variability in the Slope Water and its relation to the Gulf Stream path. Geophys Res Lett 35:L03606, doi:10.1029/2007GL032183

Pickart RS, Spall MA (2007) Impact of Labrador Sea convection on the North Atlantic meridional overturning circulation. J Phys Oceanogr 37:2207-2227

Schott FA, Fischer J, Dengler M, Zantopp R (2006) Variability of the deep western boundary current east of the Grand Banks. Geophys Res Lett 33:L21S07, 10.1029/2006GRL026563

Schweckendiek U, Willebrand J (2005) Mechanisms affecting the overturning response in global warming simulations. J Clim 18:4925-4936

Spall MA, Pickart RS (2001) Where does dense water sink? A subpolar gyre example. J Phys Oceanogr 31:810-826

Spall MA (2004) Boundary currents and water mass transformation in marginal seas. J. Phys. Oceanogr 34:1197-1213

Spall MA (2008) Buoyancy-forced downwelling in boundary currents. J Phys Oceanogr 38:2704-2721

Steele M, Morley R, Ermold W (2001) PHC: A global ocean hydrography with a high quality Arctic Ocean. J Clim 14:2079-2087

Stouffer RJ et al. (2006) GFDL's CM2 global coupled climate models. Part IV: Idealized climate response. J Clim 19:723-740

Straneo F (2006) On the connection between dense water formation, overturning, and poleward heat transport in a convective basin. J Phys Oceanogr 36:1822-1840

Straneo F, Pickart RS, Lavender K (2003) Spreading of Labrador Sea Water: An advectivediffusive study based on Lagrangian data. Deep-Sea Res I 50:701-719 
Talley LD, Reid JL, Robbins PE (2003) Data-based meridional overturning streamfunctions for the global ocean. J Clim 16:3213-3226

TeRaa L, Dijkstra H (2002) Instability of the thermohaline ocean circulation on interdecadal timescales. J Phys Oceanogr 32:138-160

Thorpe R, Gregory J, Johns T, Wood R, Mitchell J (2001) Mechanisms determining the Atlantic thermohaline circulation response to greenhouse gas forcing in a non-flux-adjusted coupled climate model. J Clim 14:3102-3116

Timmermann A, Latif M, Voss R, Groetzner A (1998) Northern Hemispheric interdecadal variability: A coupled air-sea mode. J Clim 11:1906-1931

Toole JM, Curry RG, Joyce TM, McCartneyM, Peña-Molino B (2010) Transport of the North Atlantic Deep Western Boundary Current about $39^{\circ}$ N, $70^{\circ}$ W: 2004-2008. Deep Sea Res II submitted

Trenberth KE (1984) Some Effects of Finite Sample Size and Persistence on Meteorological Statistics. Part I: Autocorrelations. Mon Wea Rev 112:2359-2368

Trenberth KE, Shea DJ (2006) Atlantic hurricanes and natural variability in 2005. Geophys Res Lett 33:L12704, doi:10.1029/2006GL026894

Vellinga M, Wu P (2004) Low-latitude freshwater influence on centennial variability of the Atlantic thermohaline circulation. J Clim 17:4498-4511

Visbeck M, Chassignet EP, Curry RG, Delworth TL, Dickson RR, Krahmann G (2003) The ocean's response to North Atlantic Oscillation variability. The North Atlantic Oscillation: Climatic Significance and Environmental Impact. Geophys Monogr No. 134 Amer Geophys Union 113-145

Winton M (1997) The Damping Effect of Bottom Topography on Internal Decadal-Scale Oscillations of the Thermohaline Circulation. J Phys Oceanogr 27:203-208

Zhang R (2008) Coherent surface-subsurface fingerprint of the Atlantic meridional overturning circulation. Geophys Res Lett 35:L20705, doi:10.1029/2008GL035463 
Zhang R, Vallis GK (2006) Impact of Great Salinity Anomalies on the low-frequency variability of the North Atlantic climate. J Clim 19:470-482

Zhang R, Vallis GK (2007) The role of bottom vortex stretching on the path of the North Atlantic Western Boundary Current and on the northern recirculation gyre. J Phys Oceanogr 37:2053-2080

Zhu X, Jungclaus J (2008) Interdecadal variability of the meridional overturning circulation as an ocean internal mode. Clim Dyn 31:731-741, DOI 10.1007/s00382-008-0383-9 


\section{Figure Captions}

Figure 1: (a) Climatological mean Atlantic meridional overturning circulation (AMOC) streamfunction from the CCSM3 T85 control integration for the years 150-699. Positive (negative) values indicate clockwise (anticlockwise). The contour interval is 2 Sv. (b) Time series of maximum annual mean AMOC strength, searched in the dashed box in (a) (500-2000 $\left.\mathrm{m}, 25-60^{\circ} \mathrm{N}\right)$. The last 250 years indicated by the thick solid box is the period examined in this study.

Figure 2: (a) Annual mean barotropic streamfunction for the years 450-699. Positive (negative) values contoured in red (blue) indicate the anti-cyclonic (cyclonic) circulation. Zero contours are in black. Contour interval is $10 \mathrm{~Sv}$. (b) Difference between the mean barotropic streamfunction of the two regimes, i.e. red noise regime (years 450-699) minus oscillatory regime (years 150399). Contour interval is $2 \mathrm{~Sv}$. (c) Winter (JFM) mean mixed layer depth (MLD) for the years 450-699. Contour interval is $200 \mathrm{~m}$. (d) As in (b) but for the winter MLD. Contour interval is $100 \mathrm{~m}$. The large green box denotes the mean convection region and the small green box is the northern convection zone (see text).

Figure 3: (a) Leading EOF pattern of the annual mean AMOC for the last 250 years, i.e. 450699, which explains $46 \%$ of the total variance. Amplitudes correspond to a one standard deviation change of the corresponding principal component (PC). The contour interval is $0.2 \mathrm{~Sv}$. (b) As in (a) but for the second EOF, which explains $13 \%$ of the total variance. (c) The leading PC. The shading is the time series of the maximum AMOC strength from the Fig. 1b. (d) As in (c) but for the second PC.

Figure 4: Power spectrum of the annual mean AMOC PC-1 time series, presented in a variancepreserving form. The best fit first order auto-regressive model (AR1) spectrum and associated 95 \% significant levels are plotted with dashed lines based on the 1-year lag autocorrelations of the index time series. 
Figure 5: First (a) and second (b) EOF and the winter (JFM) mixed layer depth, which explain 31 $\%$ and $11 \%$ of the total variance, respectively. Contour interval is $100 \mathrm{~m}$. Positive (negative) values plotted in red (blue) indicate deepening (shoaling). Zero contours are suppressed. The large green box denotes the mean convection region and the small green box the northern convection zone. (c-d) Corresponding PCs. The shading is the AMOC PC-1 from the Fig. 3c.

Figure 6: (a) Lag-regression of the annual mean upper $500 \mathrm{~m}$ density in the northern convection zone $\left(54-57^{\circ} \mathrm{N}, 38-48^{\circ} \mathrm{W}\right)$ (the convection index, black), its thermal component (red), and its haline component (blue) on the AMOC PC-1. (b) Lag-correlation of the convection index with the winter MLD PC-2 (red) and the annual mean AMOC PC-1 (black). Dashed lines indicate the $95 \%$ confidence interval. The lag is positive when convection leads.

Figure 7: (a) Leading EOF pattern of the annual mean sea-level pressure (SLP), which is the model equivalent of the North Atlantic Oscillation (NAO) pattern. This EOF mode explains 44 $\%$ of the total variance. Contour interval is $0.5 \mathrm{hPa}$. (b) Power spectrum of the corresponding PC. Note that the spectrum is presented in a variance-preserving form, but on linear axes for clarity. (c) Lag-correlation between the SLP PC-1 and the AMOC PC-1. Dashed lines indicate the 95\% confidence interval. The lag is positive (negative) when the AMOC PC-1 leads (lags).

Figure 8: Simultaneous regression of the annual mean surface fields on the annual mean NAO time series. (a) Wind stress curl. Note that the negative wind stress curl drives anti-cyclonic geostrophic gyre in the ocean. (b) Net surface heat flux. Positive anomalies denote heat transferred from ocean to atmosphere. (c) SST. (d) Evaporation minus precipitation. (e) $-1 \times$ melt water flux. (f) Sum of thermal and haline surface density flux. Positive (negative) anomalies are contoured with red (blue) lines. Zero contours are in black. Contour intervals are $1 \times 10^{-8} \mathrm{~N}$ $\mathrm{m}^{-3}, 2 \mathrm{~W} \mathrm{~m}^{-2}, 0.1^{\circ} \mathrm{C}, 0.1 \mathrm{~mm} /$ day, $0.5 \mathrm{~mm} /$ day, and $1 \times 10^{-7} \mathrm{~kg} \mathrm{~m}^{-2} \mathrm{~s}^{-1}$, respectively. Shading indicates green boxes the convection regions. 
Figure 9: Lag regression of the annual mean upper $500 \mathrm{~m}$ density on the annual mean NAO time series. The positive lags indicate that the density lags the NAO time series. Contour interval is $0.01 \mathrm{~kg} \mathrm{~m}^{-3}$. Positive (negative) anomalies are contoured in red (blue). Zero contours are in black. Shading indicates significance at the $5 \%$ level, and the green boxes the convection regions.

Figure 10: Lag regression along $56^{\circ} \mathrm{N}$ on the annual mean NAO time series for (a-c) potential density, (d-f) meridional velocity, and (g-i) vertical velocity. The positive lags indicate the NAO is leading. Contour intervals are $0.005 \mathrm{~kg} \mathrm{~m}^{-3}, 0.05 \mathrm{~cm} \mathrm{~s}^{-1}$, and $5 \times 10^{-5} \mathrm{~cm} \mathrm{~s}^{-1}$, respectively. Shading indicates significance at the $5 \%$ level.. The gray contours are climatological mean density with $0.05 \mathrm{~kg} \mathrm{~m}^{-3}$ interval. The green bars indicate the location of the northern convection zone.

Figure 11: Lag regression of the annual mean density in 1500-2500 m on the annual mean NAO index. Lags indicate that the density anomalies lag NAO. Contour interval is $0.001 \mathrm{~kg} \mathrm{~m}-3$. Positive (negative) anomalies are contoured in red (blue). Zero contours are in black. Shading indicates significance at the $5 \%$ level and the green boxes the convection regions.

Figure 12: Lag regressions of the annual mean barotropic streamfunction on the annual mean NAO time series. The positive lags indicate that the streamfunction lags NAO time series. Contour interval is $0.5 \mathrm{~Sv}$. Positive (negative) anomalies contoured in red (blue) indicate the anti-cyclonic (cyclonic) circulation. Zero contours are in black. Shading indicates significance at the $5 \%$ level. Thick gray contours are for the zero climatological mean.

Figure 13: Lag regressions of the annual mean AMOC on (a-d) the NAO index and (e-h) the convection index. Positive lags indicate that AMOC lags the index time series. The regressions on NAO is low-pass filtered to retain periods longer than 10 year, while the regressions on the 
convection is for the unfiltered annual mean fields. Contour intervals are $0.1 \mathrm{~Sv}$ for the regression on NAO and $0.2 \mathrm{~Sv}$ for the regression on convection. Shading indicates significance at the $5 \%$ level.

Figure 14: Lag correlations of the annual mean (a-c) barotropic streamfunction and (d-f) upper $500 \mathrm{~m}$ density with the convection index. Contour interval is 0.2. Positive (negative) values are plotted in red (blue). Shading indicates significance at the $5 \%$ level, and a positive lag that the convection index leads. The yellow box around the North Atlantic Current is the region for the barotropic streamfunction time series in Fig. 15 and 18.

Figure 15: Lag correlation of the two annual mean barotropic streamfunction time series with the convection index. The barotropic streamfunction time series is averaged in the convection region $\left(54-57^{\circ} \mathrm{N}, 38-48^{\circ} \mathrm{W}\right)$ for the black curve, while averaged in the North Atlantic Current $\left(44-54^{\circ} \mathrm{N}\right.$, 20-33 ${ }^{\circ}$ W: yellow box in Fig. 14) for the red curve. Dashed lines indicate the 95\% confidence interval. Positive lags indicate that the convection index leads.

Figure 16: Lag correlation of the annual mean upper 500m density (contour) and lag regression of annual mean upper 500m velocity (vector) on the convection index when the convection index leads by 7 years. Contour interval is 0.2 and positive (negative) values are in red (blue). The vector scale is shown in the lower right corner. Shadings indicate the bottom topography. The yellow line $\left(53^{\circ} \mathrm{N}, 10-18^{\circ} \mathrm{W}\right)$ denotes the location of the zonal section shown in Fig. 17.

Figure 17: Lag regression along $53^{\circ} \mathrm{N}$ (yellow line in Fig. 16) on the convection index time series when the convection leads by 7 years for (a) temperature, (b) salinity, and (c) potential density. Contour intervals are $0.1^{\circ} \mathrm{C}, 0.02 \mathrm{psu}$, and $0.02 \mathrm{~kg} \mathrm{~m}^{-3}$, respectively. Shading indicates significance at the $5 \%$ level. Positive (negative) anomalies are contoured in red (blue). Zero contours are in black. The light blue contours are climatological mean with contour intervals of $1^{\circ} \mathrm{C}, 0.2 \mathrm{psu}$, and $0.2 \mathrm{~kg} \mathrm{~m}^{-3}$, respectively. 
Figure 18: Auto-correlation of the convection index (black) and the barotropic streamfunction

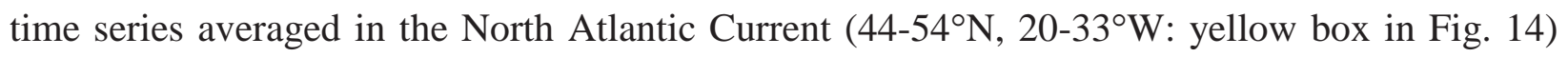
(red) for (a) years 450-699 and (b) years 150-399. Dashed lines indicate the 95\% confidence interval. 

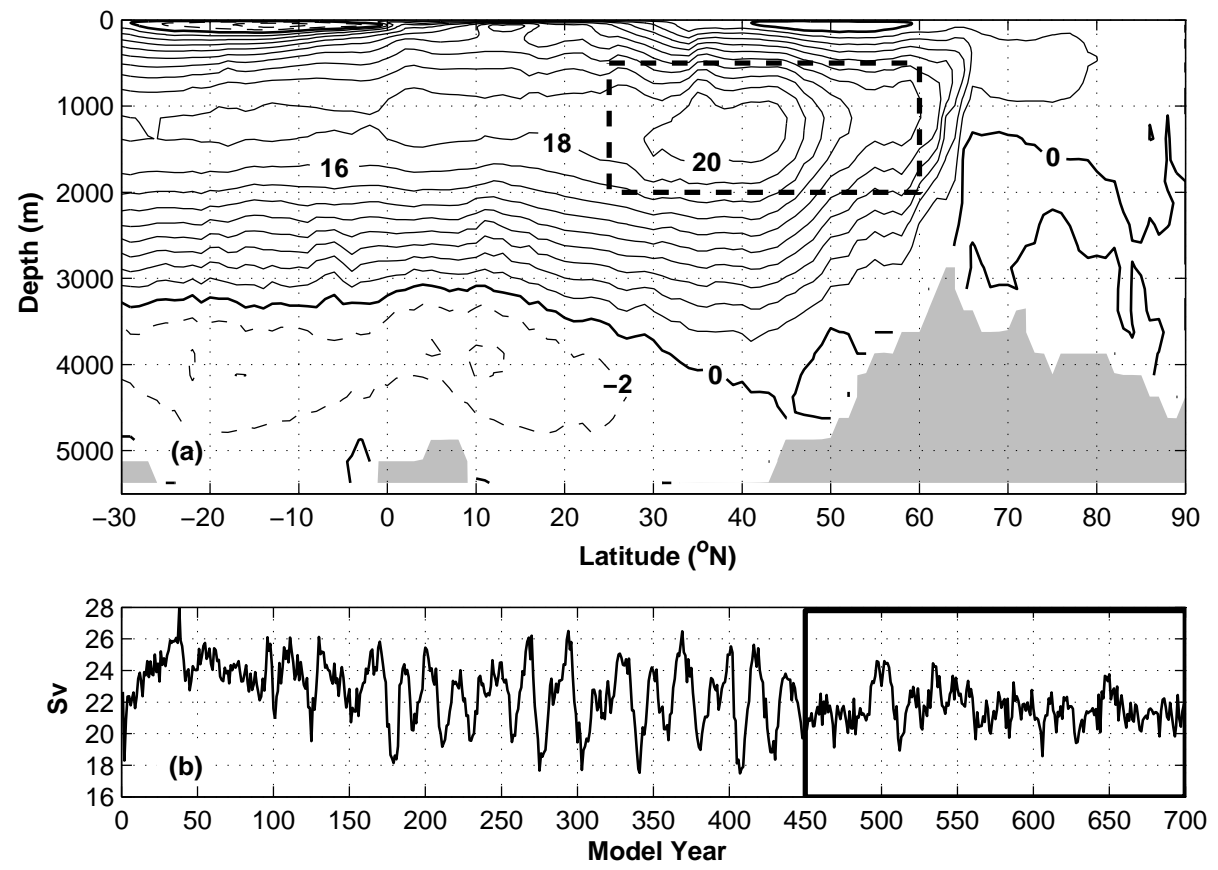

Figure 1: (a) Climatological mean Atlantic meridional overturning circulation (AMOC) streamfunction from the CCSM3 T85 control integration for the years 150-699. Positive (negative) values indicate clockwise (anticlockwise). The contour interval is $2 \mathrm{~Sv}$. (b) Time series of maximum annual mean AMOC strength, searched in the dashed box in (a) $\left(500-2000 \mathrm{~m}, 25-60^{\circ} \mathrm{N}\right)$. The last 250 years indicated by the thick solid box is the period examined in this study. 

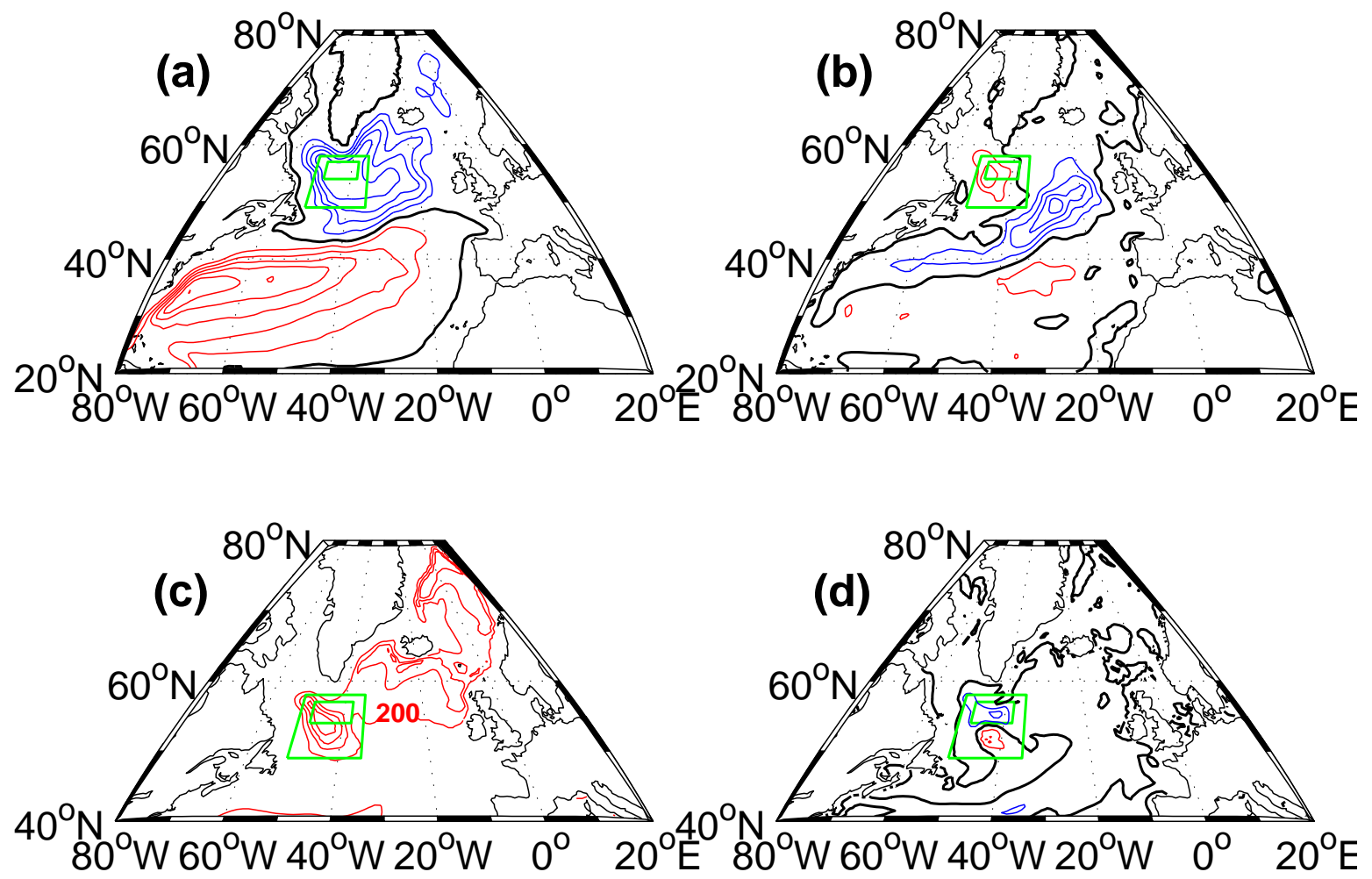

Figure 2: (a) Annual mean barotropic streamfunction for the years 450-699. Positive (negative) values contoured in red (blue) indicate the anti-cyclonic (cyclonic) circulation. Zero contours are in black. Contour interval is $10 \mathrm{~Sv}$. (b) Difference between the mean barotropic stream function of the two regimes, i.e. red noise-like regime (years 450-699) minus oscillatory regime (years 150-399). Contour interval is 2 Sv. (c) Winter (JFM) mean mixed layer depth (MLD) for the years 450-699. Contour interval is $200 \mathrm{~m}$. (d) As in (b) but for the winter MLD. Contour interval is $100 \mathrm{~m}$. The large green box denotes the mean convection region and the small green box is the northern convection zone (see text). 

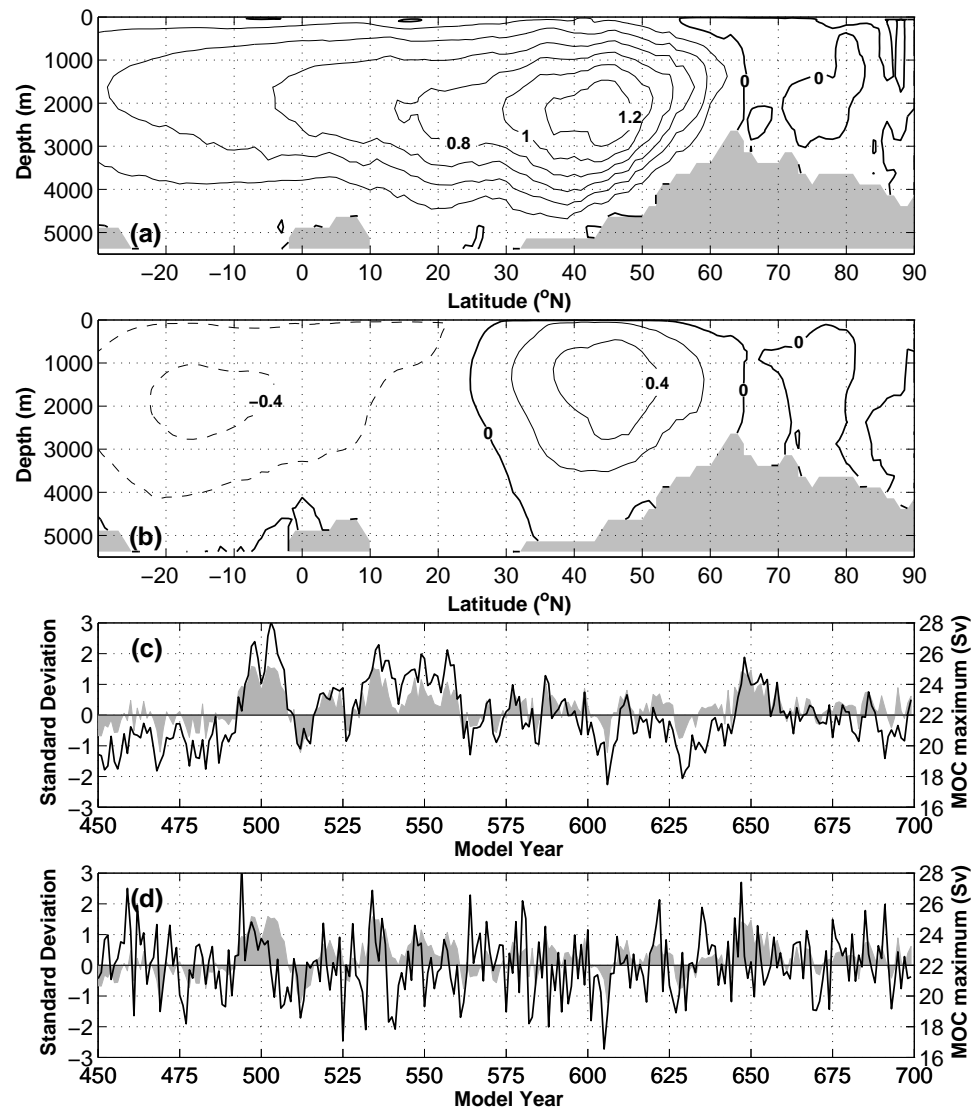

Figure 3: (a) Leading EOF pattern of the annual mean AMOC for the last 250 years, i.e. 450-699, which explains $46 \%$ of the total variance. Amplitudes correspond to a one standard deviation change of the corresponding principal component (PC). The contour interval is $0.2 \mathrm{~Sv}$. (b) As in (a) but for the second EOF, which explains $13 \%$ of the total variance. (c) The leading PC. The shading is the time series of the maximum AMOC strength from the Fig. 1b. (d) As in (c) but for the second PC. 


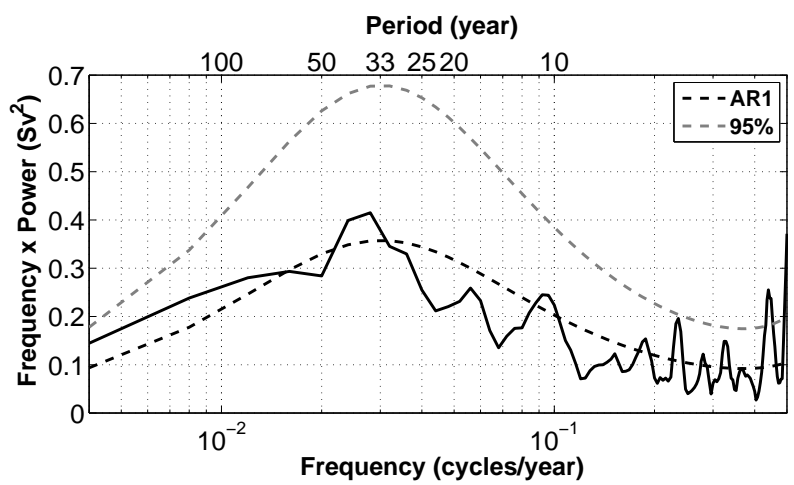

Figure 4: Power spectrum of the annual mean AMOC PC-1 time series, presented in a variance-preserving form. The best fit first order auto-regressive model (AR1) spectrum and associated $95 \%$ significant levels are plotted with dashed lines based on the 1-year lag autocorrelations of the index time series. 

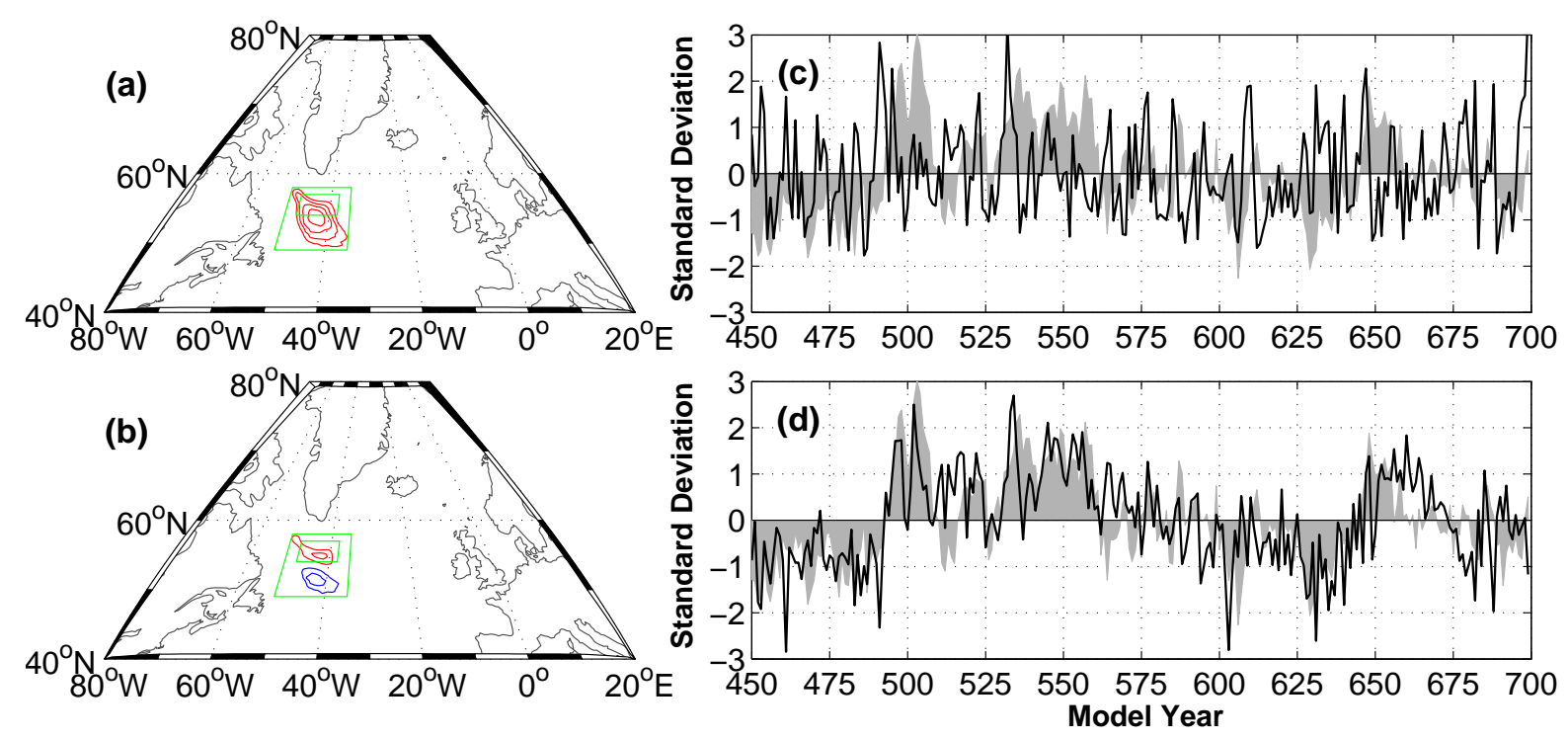

Figure 5: First (a) and second (b) EOF of the winter (JFM) mixed layer depth, which explain $31 \%$ and 11 $\%$ of the total variance, respectively. Contour interval is $100 \mathrm{~m}$. Positive (negative) values plotted in red (blue) indicate deepening (shoaling). Zero contours are suppressed. The large green box denotes the mean convection region and the small green box is the northern convection zone. (c-d) Corresponding PCs. The shading is the AMOC PC-1 from the Fig. 3c. 

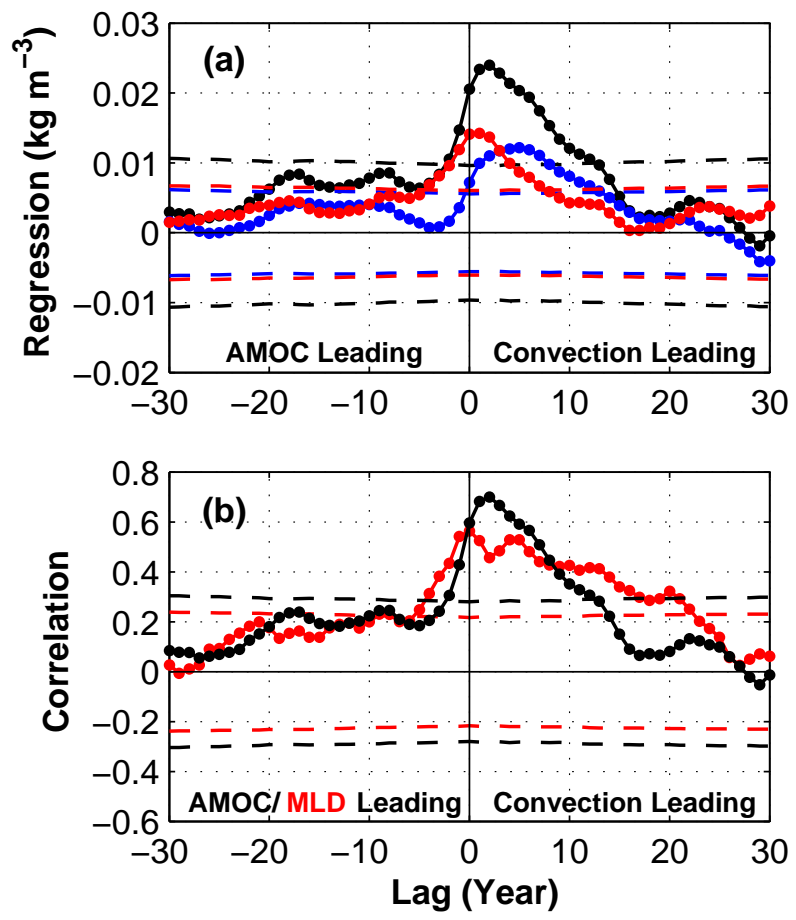

Figure 6: (a) Lag-regression of the annual mean upper 500m density in the northern convection zone (54$57^{\circ} \mathrm{N}, 38-48^{\circ} \mathrm{W}$ ) (convection index, black), its thermal component (red), and its haline component (blue) on the AMOC PC-1. (b) Lag-correlation of the convection index with the winter MLD PC-2 (red) and the annual mean AMOC PC-1 (black). Dashed lines indicate the $95 \%$ confidence interval. The lag is positive when convection leads. 


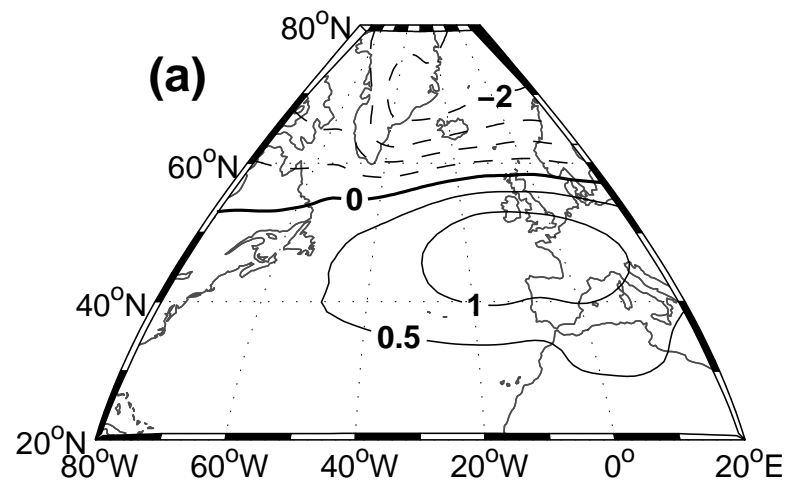

Period (year)
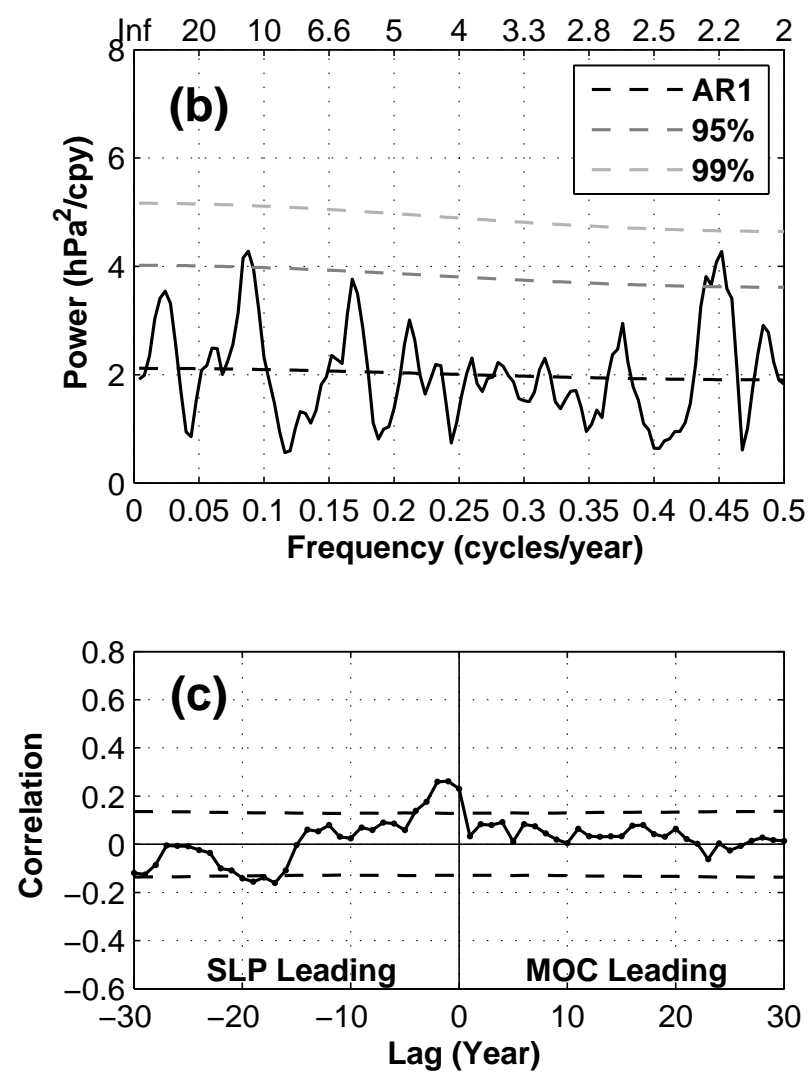

Figure 7: (a) Leading EOF pattern of the annual mean sea-level pressure (SLP), which is the model equivalent of the North Atlantic Oscillation (NAO) pattern. This EOF mode explains $44 \%$ of the total variance. Contour interval is $0.5 \mathrm{hPa}$. (b) Power spectrum of the corresponding PC. Note that the spectrum is presented in a variance-preserving form, but on linear axes for clarity. (c) Lag-correlation between the SLP PC-1 and the AMOC PC-1. Dashed lines indicate the $95 \%$ confidence interval. The lag is positive (negative) when the AMOC PC-1 leads (lags). 

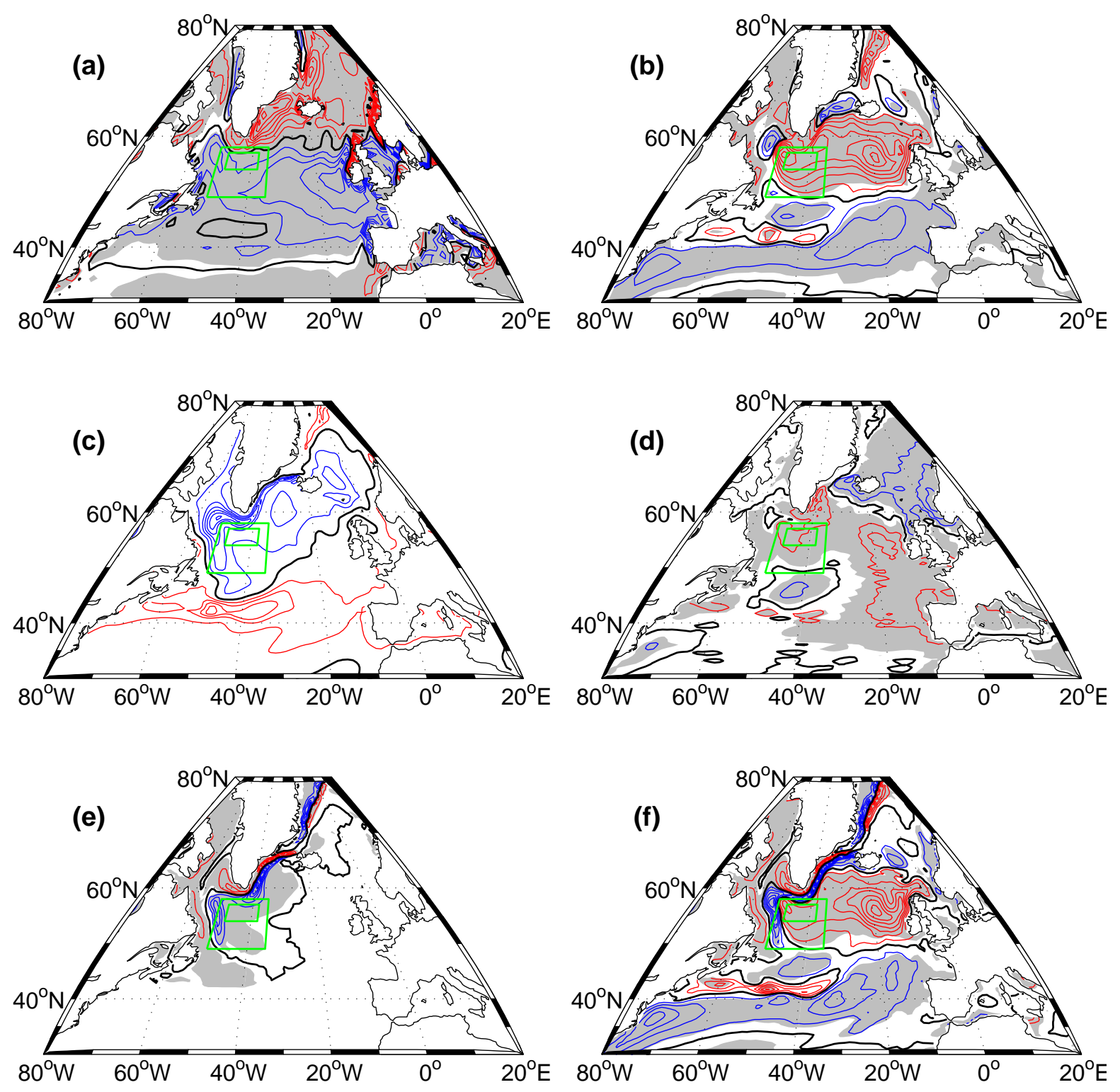

Figure 8: Simultaneous regression of the annual mean surface fields on the annual mean NAO time series. (a) Wind stress curl. Note that the negative wind stress curl drives anti-cyclonic geostrophic gyre in the ocean. (b) Net surface heat flux. Positive anomalies denote heat transferred from ocean to atmosphere. (c) SST. (d) Evaporation minus precipitation. (e) $-1 \times$ melt water flux. (f) Sum of thermal and haline surface density flux. Positive (negative) anomalies are contoured with red (blue) lines. Zero contours are in black. Contour intervals are $1 \times 10^{-8} \mathrm{~N} \mathrm{~m}^{-3}, 2 \mathrm{~W} \mathrm{~m}^{-2}, 0.1^{\circ} \mathrm{C}, 0.1 \mathrm{~mm} /$ day, $0.5 \mathrm{~mm} /$ day, and $1 \times 10^{-7} \mathrm{~kg} \mathrm{~m}^{-2}$ $\mathrm{s}^{-1}$, respectively. Shading indicates significance at the $5 \%$ level and the green boxes the convection regions. 

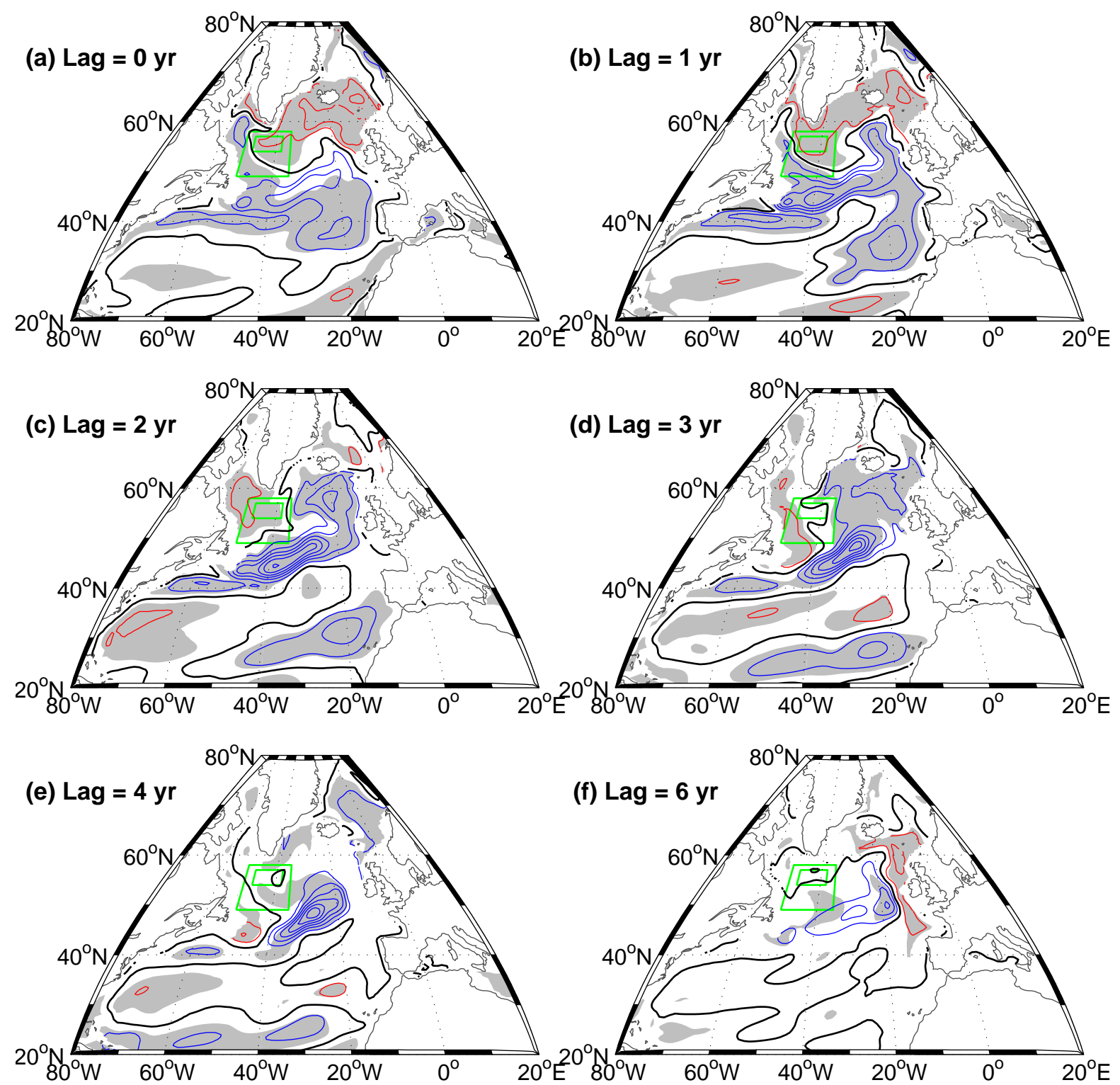

Figure 9: Lag regression of the annual mean upper $500 \mathrm{~m}$ density on the annual mean NAO time series. The positive lags indicate that the density lags the NAO time series. Contour interval is $0.01 \mathrm{~kg} \mathrm{~m}^{-3}$. Positive (negative) anomalies are contoured in red (blue). Zero contours are in black. Shading indicates significance at $5 \%$ level, and the green boxes the convection regions. 

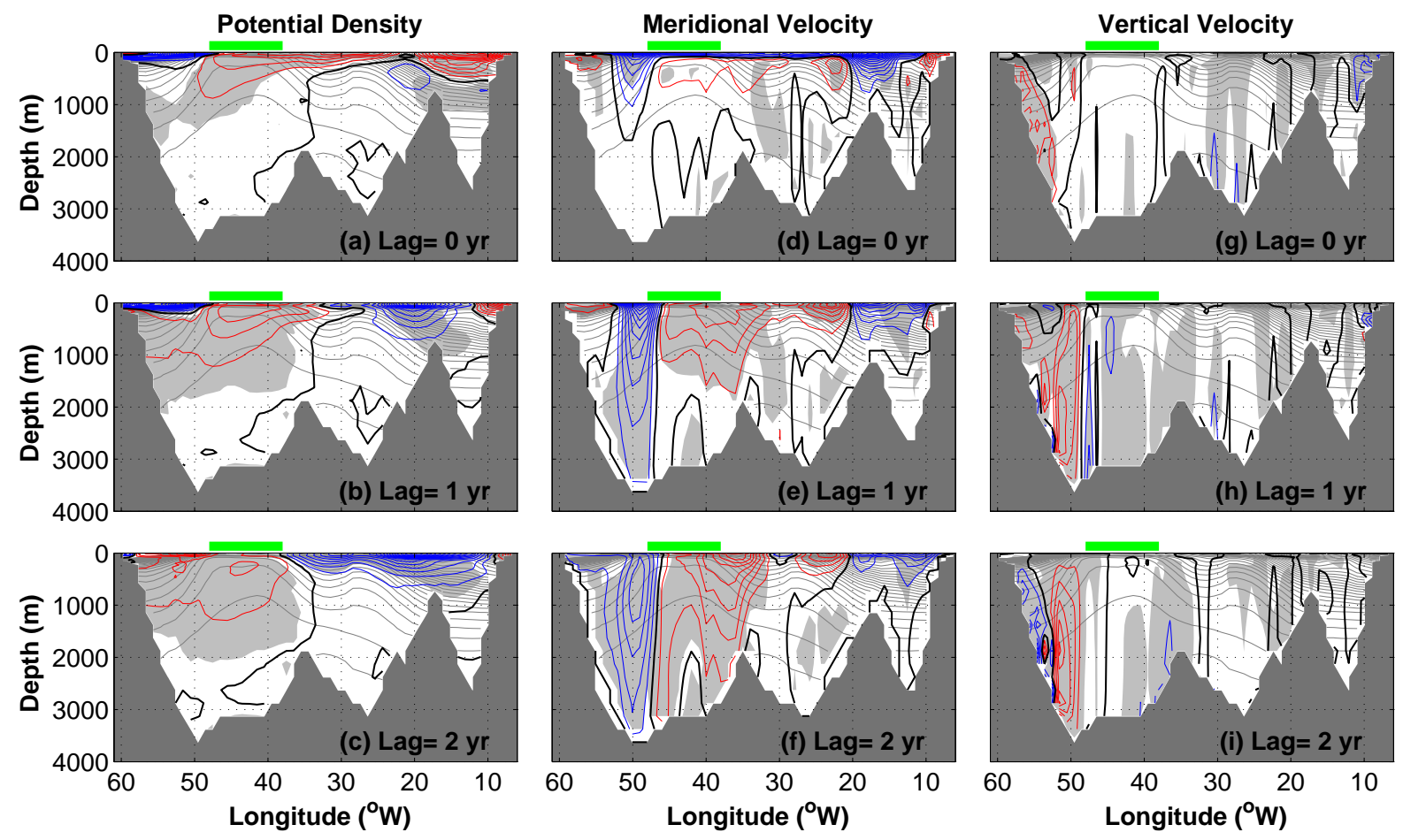

Figure 10: Lag regression along $56^{\circ} \mathrm{N}$ on the annual mean NAO time series for (a-c) potential density, (d-f) meridional velocity, and (g-i) vertical velocity. The positive lags indicate the NAO is leading. Contour intervals are $0.005 \mathrm{~kg} \mathrm{~m}^{-3}, 0.05 \mathrm{~cm} \mathrm{~s}^{-1}$, and $5 \times 10^{-5} \mathrm{~cm} \mathrm{~s}^{-1}$, respectively. Shading indicates significance at $5 \%$ level. The gray contours are climatological mean density with $0.05 \mathrm{~kg} \mathrm{~m}^{-3}$ interval. The green bars indicate the location of the northern convection zone. 

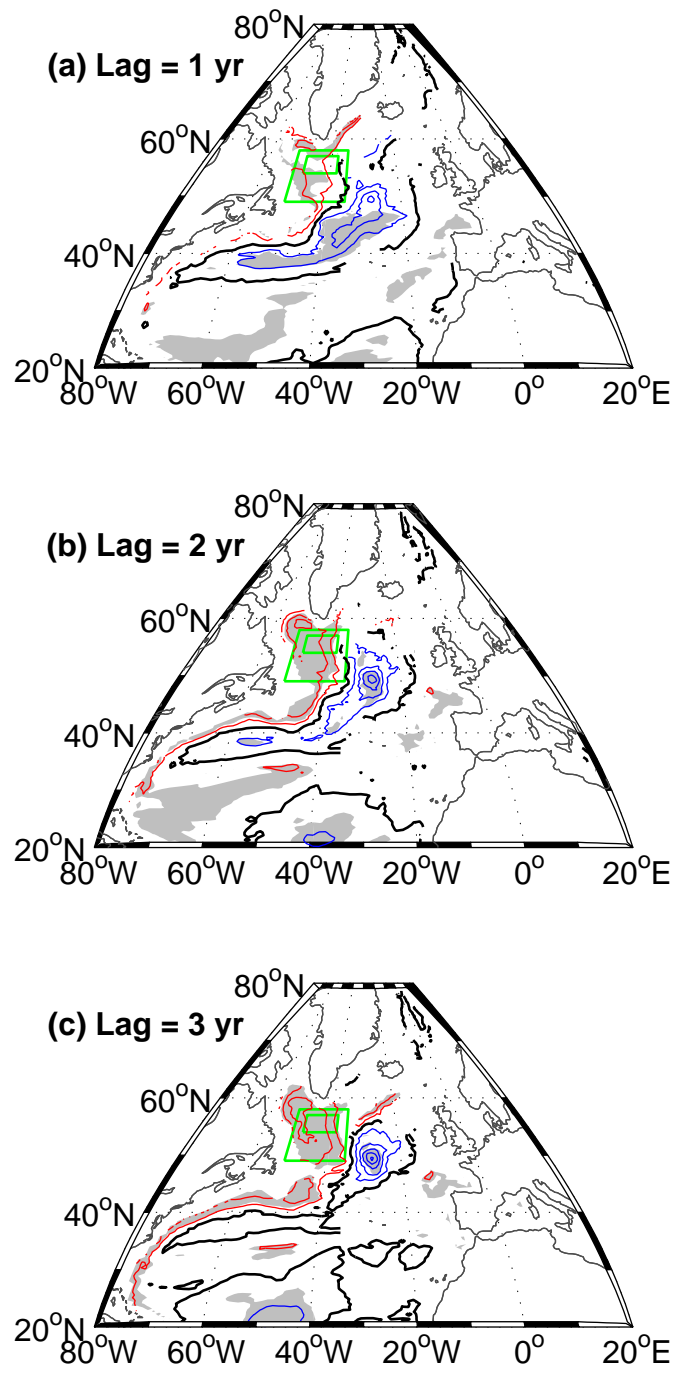

Figure 11: Lag regression of the annual mean density in $1500-2500 \mathrm{~m}$ on the annual mean NAO index. Lags indicate that the density anomalies lag NAO. Contour interval is $0.0005 \mathrm{~kg} \mathrm{~m}^{-3}$. Positive (negative) anomalies are contoured in red (blue). Zero contours are in black. Shading indicates significance at $5 \%$ level and the green boxes the convection regions. 

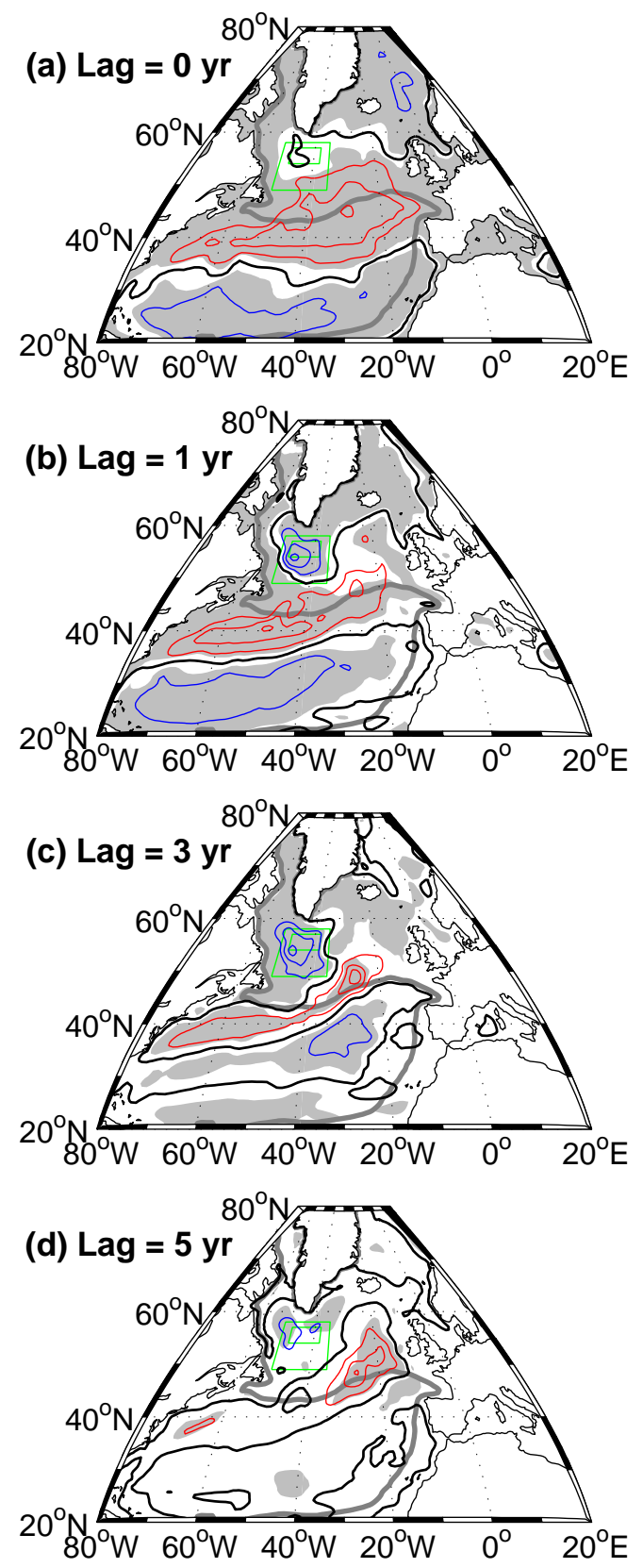

Figure 12: Lag regressions of the annual mean barotropic streamfunction on the annual mean NAO time series. The positive lags indicate that the streamfunction lags NAO time series. Contour interval is 0.5 Sv. Positive (negative) anomalies contoured in red (blue) indicate the anti-cyclonic (cyclonic) circulation. Zero contours are in black. Shading indicates significance at $5 \%$ level. Thick gray contours are for the zero climatological mean. 

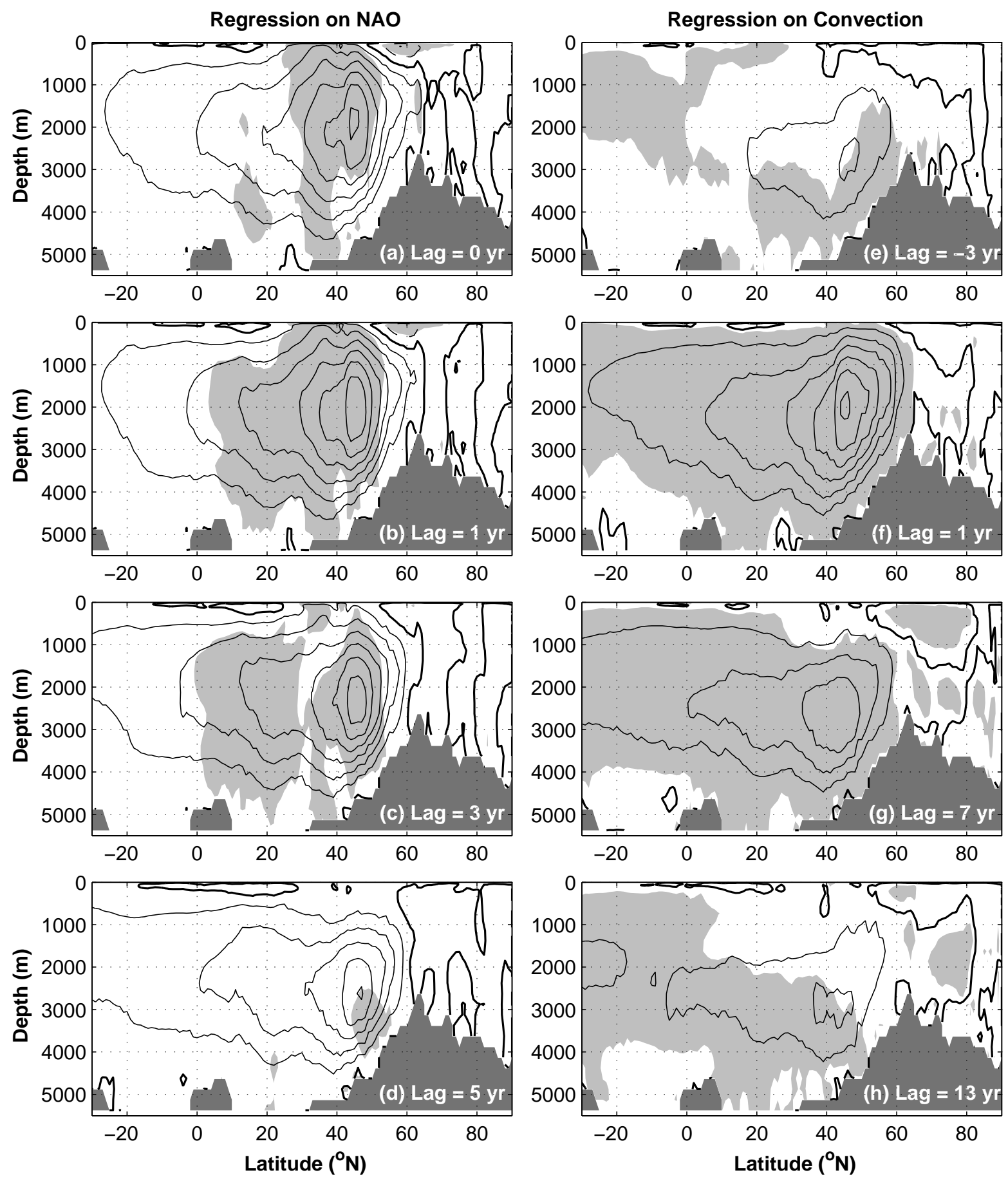

Figure 13: Lag regressions of the annual mean AMOC on (a-d) the NAO index and (e-h) the convection index. Positive lags indicate that AMOC lags the index time series. The regressions on NAO is low-pass filtered to retain periods longer than 10 year, while the regressions on the convection is for the unfiltered annual mean fields. Contour intervals are $0.1 \mathrm{~Sv}$ for the regressions on NAO and $0.2 \mathrm{~Sv}$ for the regressions on convection. Shading indicates significance at $5 \%$ level. 


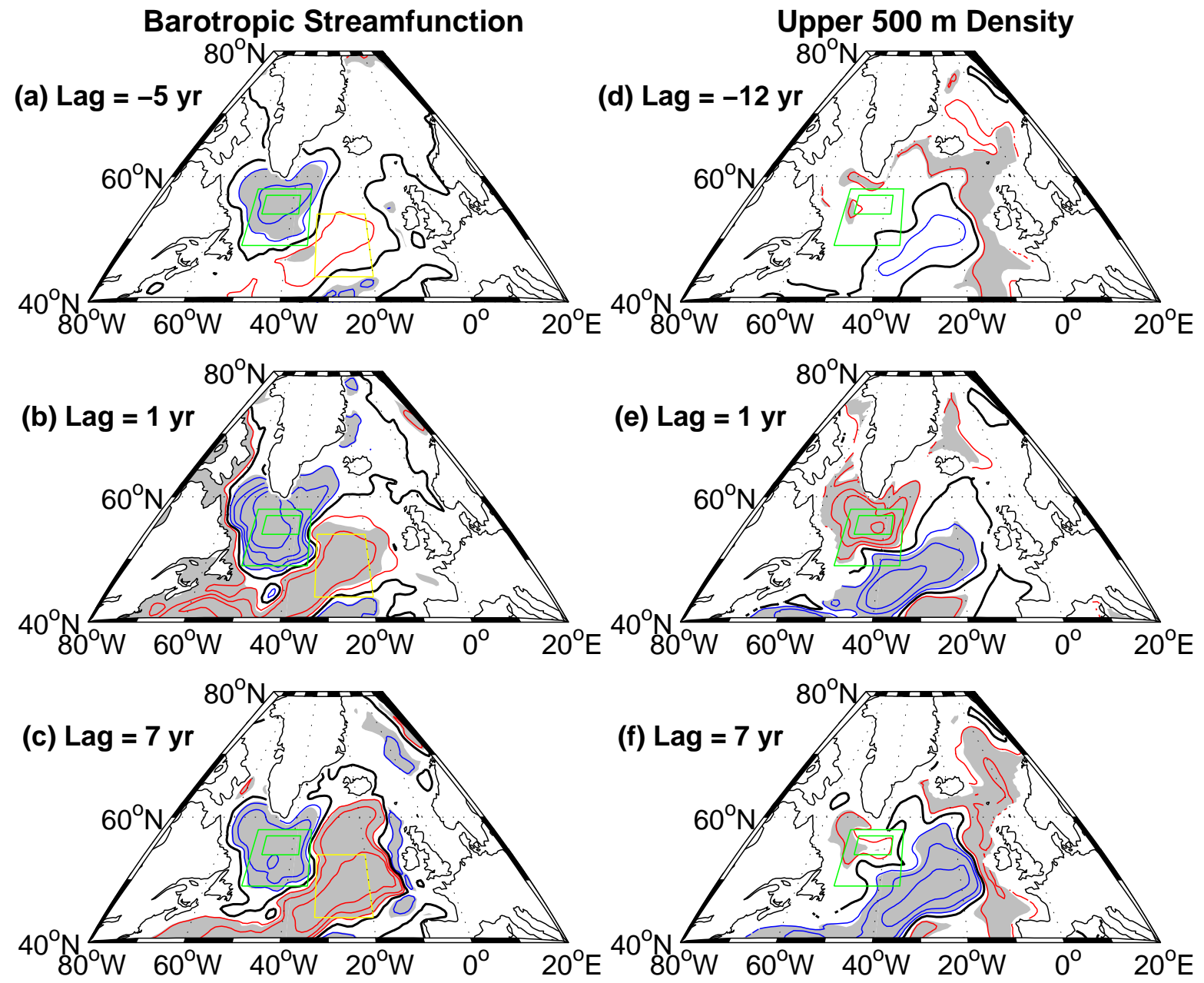

Figure 14: Lag correlations of the annual mean (a-c) barotropic streamfunction and (d-f) upper $500 \mathrm{~m}$ density with the convection index. Contour interval is 0.2. Positive (negative) values are plotted in red (blue). Shading indicates significance at $5 \%$ level, and a positive lag that the convection index leads. The yellow box around the North Atlantic Current is the region for the barotropic streamfunction time series in Fig. 15 and 18. 


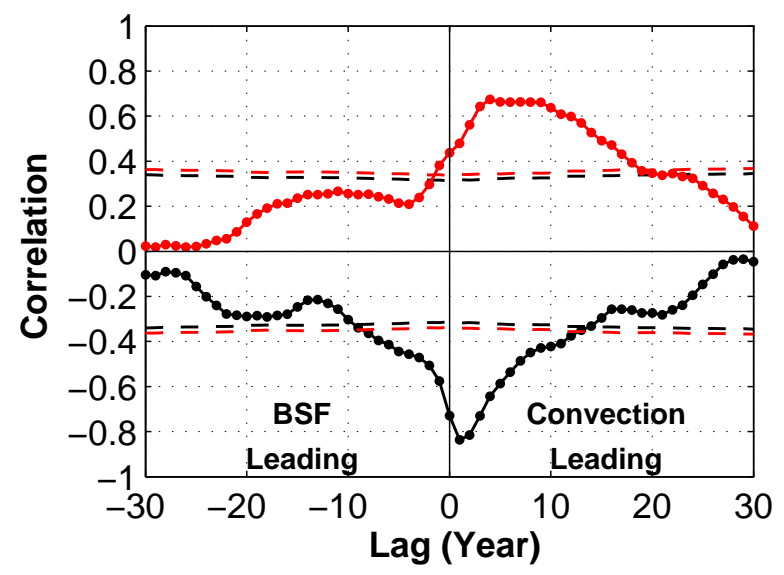

Figure 15: Lag correlation of the two annual mean barotropic streamfunction time series with the convection index. The barotropic streamfunction time series is averaged in the convection region $\left(54-57^{\circ} \mathrm{N}, 38-48^{\circ} \mathrm{W}\right)$ for the black curve, while averaged in the North Atlantic Current $\left(44-54^{\circ} \mathrm{N}, 20-33^{\circ} \mathrm{W}\right.$ : yellow box in Fig. 14) for the red curve. Dashed lines indicate the $95 \%$ confidence interval. Positive lags indicate that the convection index leads. 


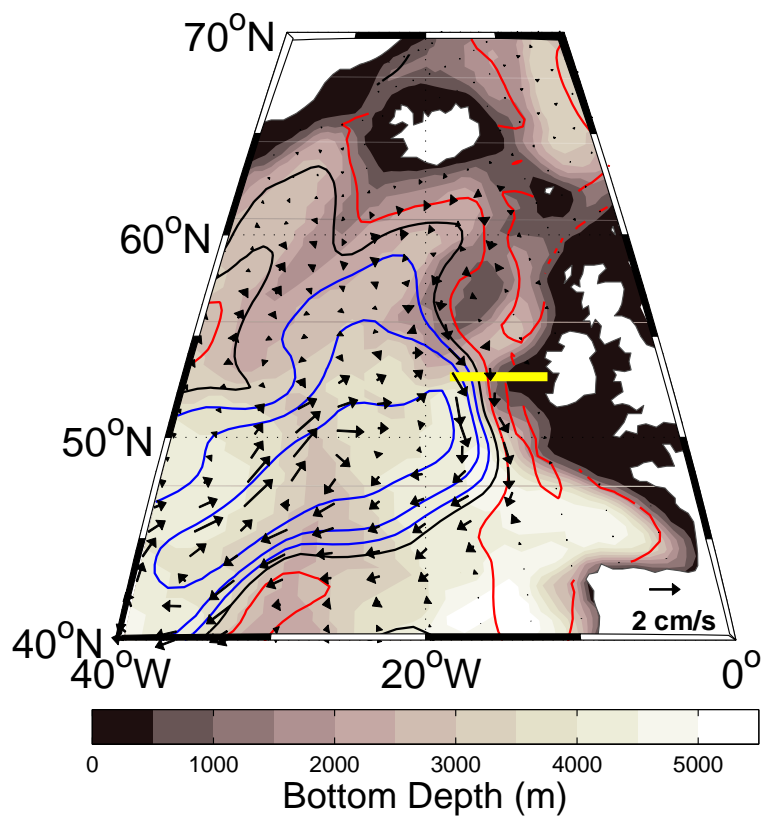

Figure 16: Lag correlation of the annual mean upper 500m density (contour) and lag regression of annual mean upper $500 \mathrm{~m}$ velocity (vector) on the convection index when the convection index leads by 7 years. Contour interval is 0.2 and positive (negative) values are in red (blue). The vector scale is shown in the lower right coner. Shadings indicate the bottom topography. The yellow line $\left(53^{\circ} \mathrm{N}, 10-18^{\circ} \mathrm{W}\right)$ denotes the location of the zonal section shown in Fig. 17. 

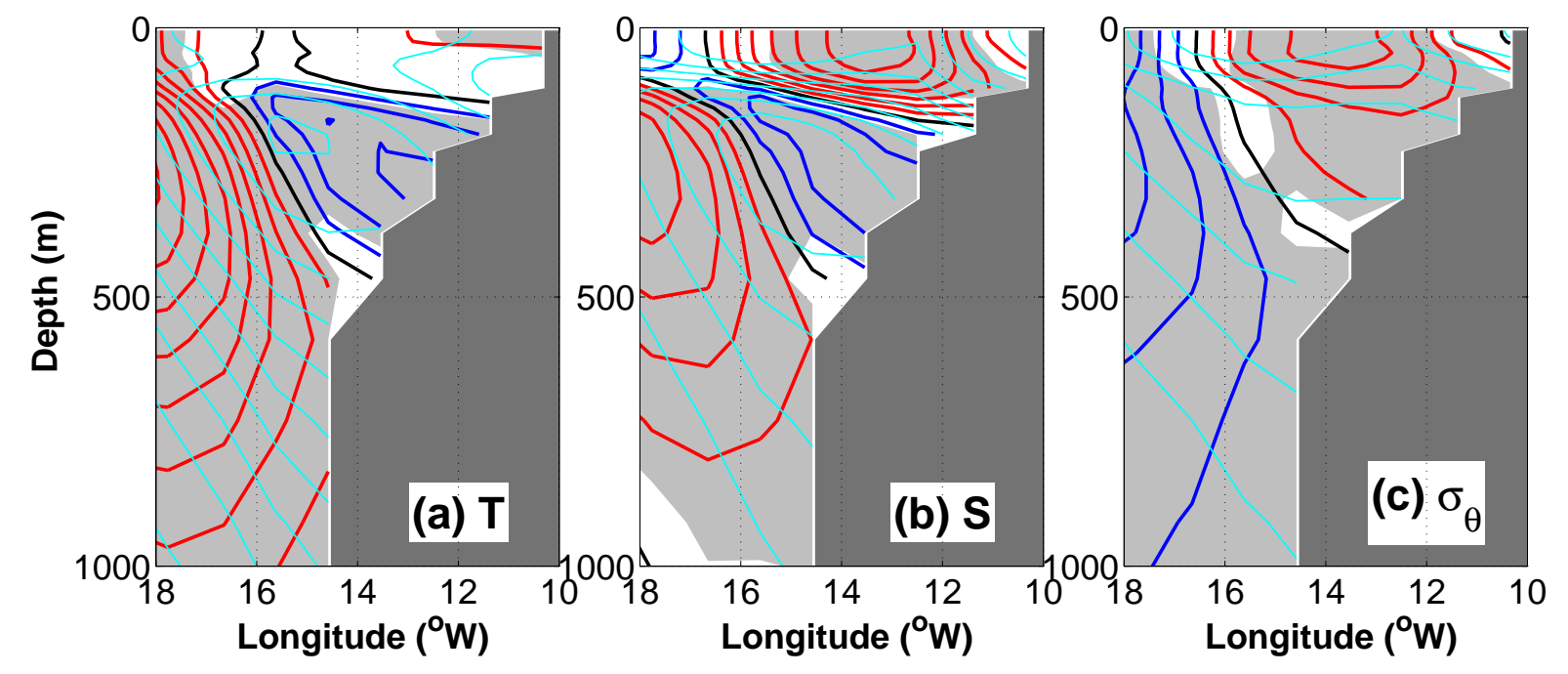

Figure 17: Lag regression along $53^{\circ} \mathrm{N}$ (yellow line in Fig. 16) on the convection index time series when the convection leads by 7 years for (a) temperature, (b) salinity, and (c) potential density. Contour intervals are $0.1^{\circ} \mathrm{C}, 0.02 \mathrm{psu}$, and $0.02 \mathrm{~kg} \mathrm{~m}^{-3}$, respectively. Shading indicates significance at $5 \%$ level. Positive (negative) anomalies are contoured in red (blue). Zero contours are in black. The light blue contours are climatological mean with contour intervals of $1^{\circ} \mathrm{C}, 0.2 \mathrm{psu}$, and $0.2 \mathrm{~kg} \mathrm{~m}^{-3}$, respectively. 

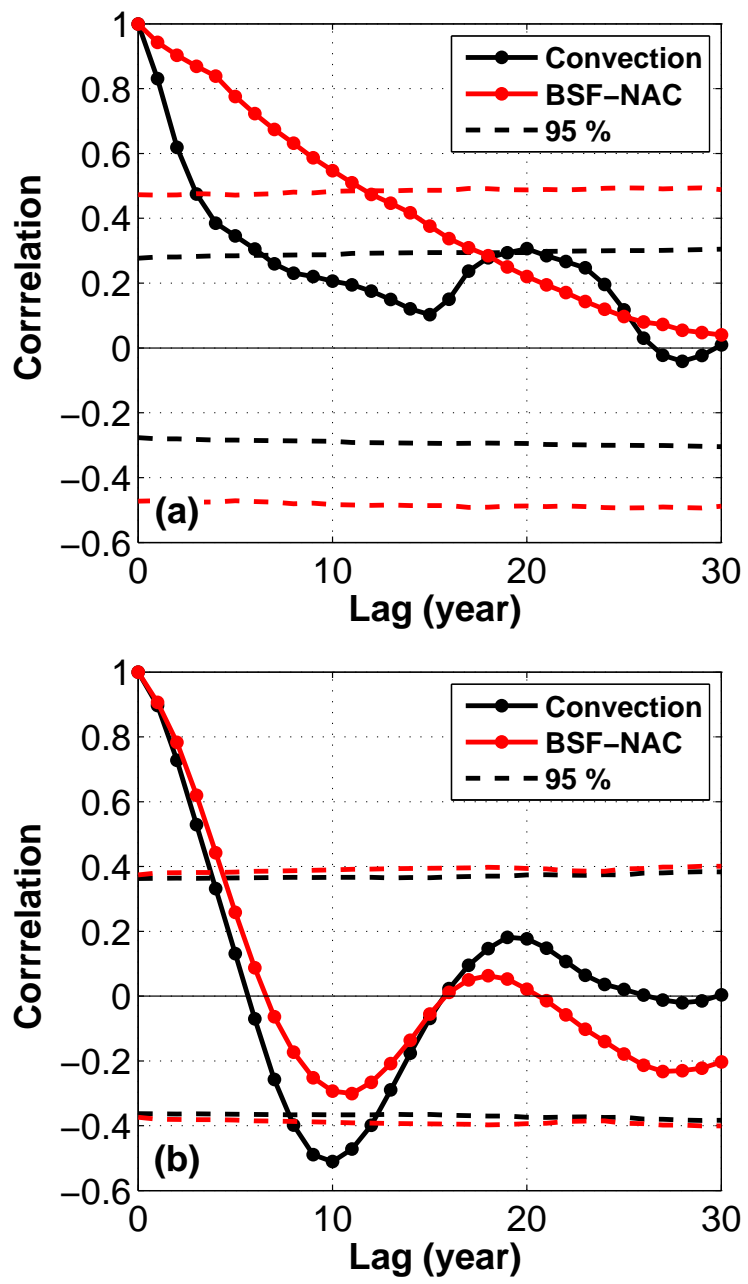

Figure 18: Auto-correlation of the convection index (black) and the barotropic streamfunction time series averaged in the North Atlantic Current (44-54 $\mathrm{N}, 20-33^{\circ} \mathrm{W}$ : yellow box in Fig. 14) (red) for (a) years 450-699 and (b) years 150-399. Dashed lines indicate the $95 \%$ confidence interval. 